\title{
Compression of the Material Characteristics of Steel, Aluminum, Wood and Woven Graphite Epoxy Composites in Response to High Strain Rate Load
}

\author{
M. R. Allazadeh ${ }^{* 1}$, M. K. Itani ${ }^{2}$, S. N. Wosu ${ }^{2}$ \\ ${ }^{* 1}$ Hungarian Academy of Sciences Konkoly-Thege út 29-33 1121 mta-ttk-mfa, Budapest, Hungary \\ ${ }^{2}$ University of Pittsburgh, Mechanical Engineering Department, Pittsburgh PA, 15261, USA \\ allazadeh@mfa.kfki.hu
}

\begin{abstract}
The stresses developed in the material by impact load are analyzed experimentally, numerically, and analytically for specimens out of steel, aluminum, wood and woven graphite epoxy composites to investigate the material response to high strain rate stresses for aforementioned materials. The applied strain rates in experiments were set to be within 950 and 3500 s-1. The thin circular shape specimens were examined with high strain rate laboratory tests using the perforation split Hopkinson pressure bar (P-SHPB) with dimensional ratio accepted for One-dimensional stress analysis hypothesis. The article describes analytical solutions for one dimensional in detail to be implemented for numerical analyzing via trapezoid computation. The graphs of the four listed materials with two different thicknesses are compared for the specimen's energy absorbed, specimen's strain rate, stress strain rate relationship of the specimen, maximum energy absorbed, and maximum strain in specimen. It turned out that the dependency of deformation on energy absorption follows a power law for the woven composite and is approximated with linear relationships for aluminum and steel. Studying the effect of thickness in energy absorbed shows that doubling the thickness of the specimen reduces the strain of the specimen by 50 percentages for woven graphite epoxy and wood specimens, but the reduction is 25 percentages in the steel and aluminum specimens.
\end{abstract}

Keywords- Compression Test; High Strain Rate; P-SHPB; Fiber Structure; Damage Mode

\section{INTRODUCTION}

Characteristics of dynamic load damage are of interest in many industrial applications especially in military ones where rapid damage may be catastrophic or desirable based on the application of the design. Compression load generates damage on specimen material due to high rate material displacement in Charpy test, Izod test, split Hopkinson (Kolsky) and split Hopkinson pressure bar (SHPB). Many researchers ${ }^{[1-30]}$ have studied the material behavior under compressive load. This article compares the material behavior of steel, aluminum, wood and woven graphite epoxy composites under high compression impact. Great deal of research works ${ }^{[1-3]}$ have been done to perceive the mechanical properties of steel under high strain rate loading. Yu and Topper ${ }^{[4]}$ studied the effect of compressive load for the tempered and quenched steel's mechanical behavior. They announced that both compressive and intermittent compressive loads decrease the threshold and accelerate near the threshold crack's growth rate. Yoshida's results ${ }^{[5]}$ showed stress-strain relationship of two different kinds of steel using cyclic tension-compression at large strain. He concluded that large strain range affects the amount of stress in the specimen. Work has also been done to form a full appreciation of the aluminum tolerance region ${ }^{[6-10]}$. Jia ${ }^{[11]}$ studied aluminum specimens using miniaturized Kolsky bar and compared the results with the traditional Kolsky bar and numerical analysis. He suggested that the results of the tests could be acceptable only with efficient lubrication before experiments to eliminate the influence of surface friction. Lee ${ }^{[12]}$ studied the high strain rate behavior of aluminum foam material and 304 stainless steel using dynamic loading and quasi-static loading to investigate different failure mechanisms. He concluded that the deformation caused by quasi bar was more concentrated than that of dynamic loading. Jia and Lee, both gave stressstrain relationship for aluminum at high strain rate, however, the effect of specimen dimension on type of dynamic failure were ignored in their results. Vural's [13] experiment provided good information about stress-strain relationship of wood using modified Kolsky bar. In his experiment, specimens were compression loaded along the grain direction. He showed that the loading rate has essential effect in the initial failure stress. Cantero ${ }^{[14]}$ said that the fiber structure of wood and the hydrophilic nature of the cellulose determine the dispersion and moisture, which affect the stress-strain relationship. Since wood has somewhat different mechanical behavior, more research ${ }^{[15-}$ ${ }^{17]}$ was crucial. In this paper, wider range of energy levels was applied for two different circular specimens' thicknesses out of wood using traditional Hopkinson bar to compare its behavior as material with natural fibers with woven graphite epoxy as material with fabricated fibers. Many works ${ }^{[18-25]}$ have been done on graphite epoxy composites in the past two decades to better understand its mechanical properties such as shearing, fatigue, elastic, transverse and tensile properties. Bamisaye ${ }^{[26]}$ used split Hopkinson bar device with different penetrators to find the threshold energy for three different thicknesses of woven composites. He uttered that crack propagates in thinner specimens is faster than thicker ones. Previous laboratory works proved that depending on the nature of the penetrator head, conical hemispherical penetrator was found to be more effective in penetrating or perforating the composite plate than spherical penetrator ${ }^{[27]}$. The authors ${ }^{[28-30]}$ have analyzed the high-energy penetration/perforation mechanics of steel, aluminum, wood and the woven graphite epoxy 
composites individually and confirmed that for all of these materials, strain rate, ultimate strain, and energy absorption increase with increasing perforation energy.

The previous research on steel, aluminum, composites and wood contribute to the body of knowledge of behavior of these materials in response to high strain rate dynamic loading. However, there is limited documentation of the comparison of woven graphite epoxy composites with the metallic structure of steel, aluminum and natural fiber structure material such as wood. In addition, the experimental results in this paper analyze the effect of thickness of the specimen for material response to the impact load. In this research work, perforation-SHPB (PSHPB) is deployed to perceive mechanical behavior of the selected candidate materials possessing different mechanical strength property and microstructure.

\section{THEORETICAL BACKGROUND}

The mechanical wave is the stress wave pulse propagating with a wave velocity that is characteristic of the medium through which it propagates. The mechanical waves impose the medium particles to displace from their equilibrium position. Localized mechanical disturbance generates a mechanical wave in a solid, which propagates from one section to another. The source of the mechanical wave is the abrupt deviation in the state of the boundary condition of the input bar, or so-called the incident bar, due to impact of striker bar, therefore, wave characteristics depend on boundary conditions. When a propagating mechanical wave reaches a boundary that is neither free, nor fixed (e.g., the boundary between two dissimilar materials), a fraction of the wave is reflected at the interface between the specimen and the incident bar due to an impedance mismatch at the interface. Meanwhile, the remainder of the wave is transmitted to the output bar known as transmitter bar. The amplitude of the reflected wave depends on the interface and specimen properties, e.g. the surface damage or roughness on the specimen, and suggests mechanical information about materials interaction at the interface.

For a free boundary surface, a compressive incident wave is reflected wholly as a tension wave, and vice versa. If the interaction is at a fixed boundary, a compressive or tension wave is reflected with no change in shape, phase, or intensity. A simplified schematic of the wave propagation is shown in Fig. 1.

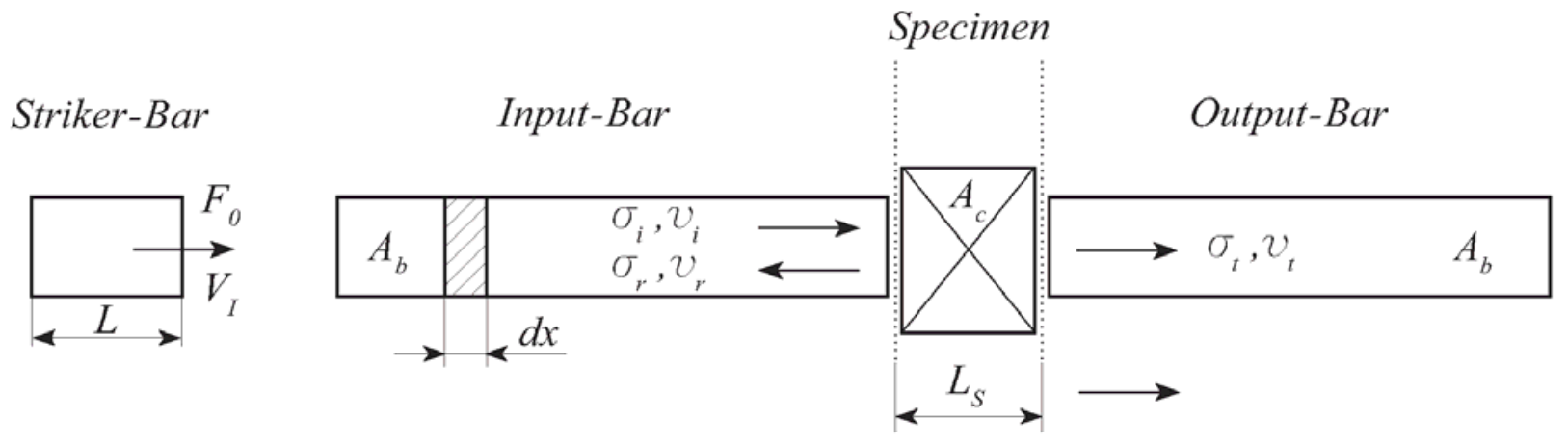

Fig. 1 Schematics illustration of wave propagation

The wave train is considered as the propagation of the disturbance or vibration of the particles, and hereby, the strength of a material is determined by the highest amplitude of stress wave which material can withstand without failing. Thereof, accurate measurements of the wave pulse in dynamic impact studies are important. This disturbance is utilized to characterize the damage process and its dependency on the wave, materials and impact properties and especially the time dependent states such as particle's velocity, strain, and stress.

A wave is dispersive if it changes its shape while within the components which travels through at different velocities. Issues rated to the effect of dispersion in a SHPB at high strain rate are worthy of verification because composite materials undergo elastic deformation under dynamic or non-uniform loading conditions, making it possible for the pulse to change in amplitude and duration during transmission through the specimen. For a longitudinal stress wave, the particle displacement is along a line parallel to the direction of wave propagation. A wave in a rod is considered longitudinal when Poisson's effect and the associated radial particle velocity are negligible.

\section{EXPERIMENTAL DETAIL}

The modified SHPB apparatus used in this experiments consists of incident, transmitter, and striker bars (300 maraging AMS 6414 steel), each being $25.4 \mathrm{~mm}$ in diameter. The incident and transmitter bars are $3.66 \mathrm{~m}$ in length, while the striker bar is $0.305 \mathrm{~m}$ long. The striker is housed inside a $0.610 \mathrm{~m}$ launch cylinder and is driven by compressed air of up to $1.72 \mathrm{MPa}$. To begin each test, the desired pressure is manually set using a gauge between the launch cylinder and the reservoir. A switch in the control room activates the opening of a quick-acting solenoid valve and controls the acceleration of the striker into the incident bar. The quick acting solenoid valve allows a preset amount of air stored in the cylinder to pass through it when the switch is closed during operation. The geometrical shape of the striker and the impact velocity control the shape of the waveform.

The impact-end of the striker is spherically rounded with a $50.8 \mathrm{~m}$ radius for a repeatable point of contact with the incident bar on a plane centrally normal to the longitudinal direction of the wave propagation. Proper axial alignment between the striker and incident bars is insured to minimize 
flexure. The uniaxial waveform generated in the bar determines the rate at which energy is transferred from the bar to the plate of specimen.

The stress wave amplitude varies with impact velocity, while the stress profile changes with striker geometry. Incident and transmitter bars are guided through pillow blocks containing low-friction ball bearings. The bushings (mounted on a rigid steel channel, which is backed-up by an I-beam) support the bar shifts without restraining them. The support can be adjusted laterally and vertically for proper alignment. To minimize vibration, the unit is anchored to steel beams running through a $102 \mathrm{~mm}$ steel-reinforced concrete deck. A $6.35 \mathrm{~mm}$ diameter rod is attached to one end of the striker such that it protrudes outside the cylinder as a means of adjusting the stroke length, and therefore, striker velocity. Venting holes along the launch tube maintain a low-pressure zone in front of the striker and prevent the possibility of multiple impacts. The data acquisition system shown consists of two Nicolet Pro 42 high-speed digital oscilloscopes. Incident, reflected, and transmitted waves are recorded at a rate of 20 million samples per second and stored in a PC storage device. The system has 12 -bit digitizer offering $0.025 \%$ resolution and a storage capability of 250,000 samples per channel with its 26 megabytes of RAM. The signal analysis could be completed using a Nicolet spectrum analyzer, a special Lotus or Excel scheme developed for numerical integration to get information about the strain and stress at each component of the bar and specimen using shunt calibration. The strain wave incident, reflected, and transmitted pulses provide information for complete characterization of the damage process. The integration of the strain wave gives the energy absorbed-time history, force-displacement, stressstrain relationship and other relevant data to characterize the specimen damage Fig. 2 shows different parts of the PSHPB testing instrument

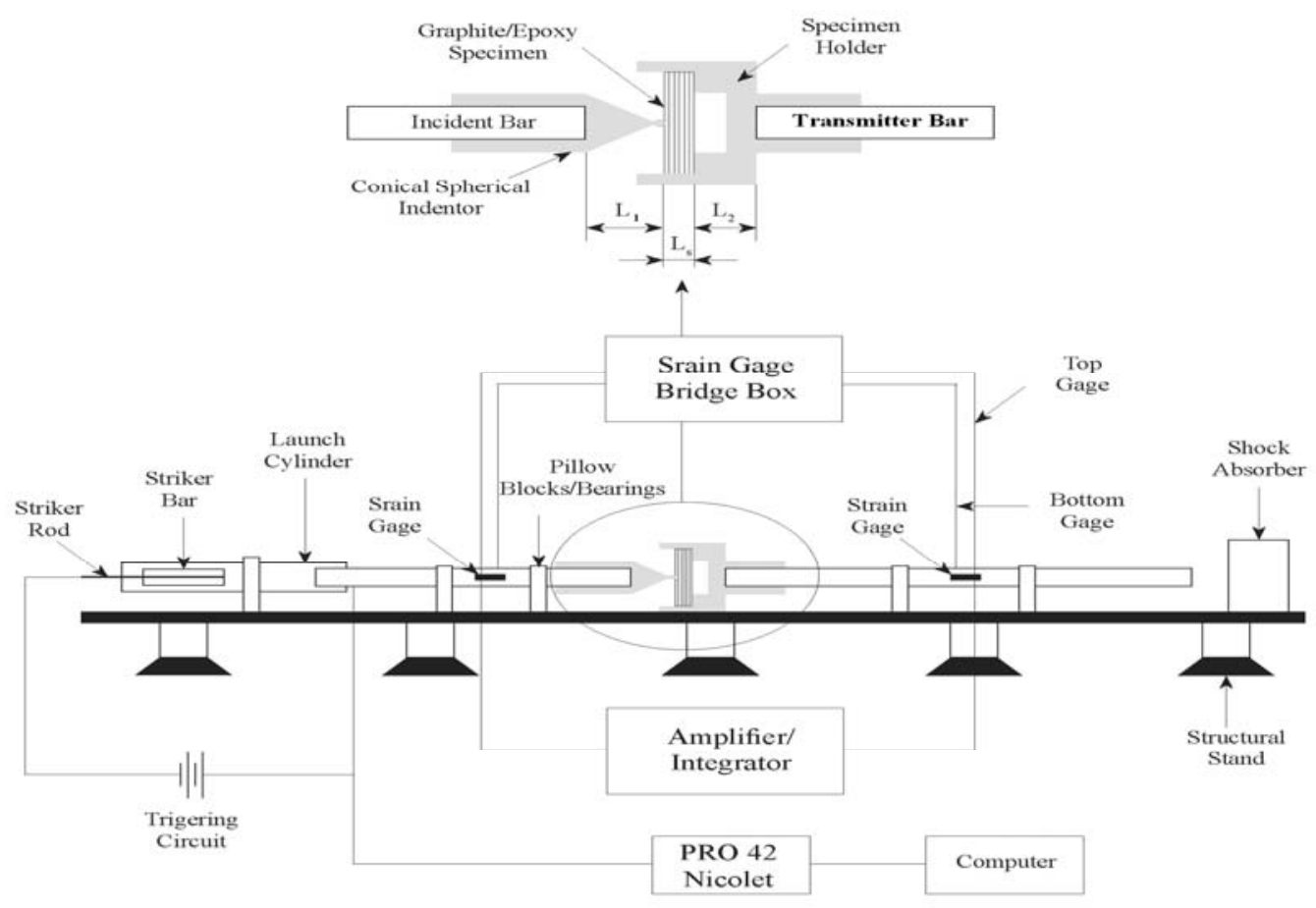

Fig. 2 Modified split Hopkinson bar with details of the striker launch cylinder and test specimen interfaces

In the P- SHPB system used in this work, compressed air launches the striker bar against the incident bar at a specific energy level and forms a longitudinal wave that travels along the incident bar. Boundary conditions determine the characteristics of the captured wave. In the case of neither free nor fixed boundary conditions, a portion of the stress waves are reflected from the end of the transmitted bar in direction opposite to initial applied stress. The striker velocity, just before collision with the incident bar, was measured as a function of impact pressure using two infrared photo gate detectors, which detect the motion of

$$
v_{i}=0.0014 p^{0.7007}
$$

two sensors glued on the bars. One was placed on the incident bar and the second one was attached to the transmitted bar. Ojo ${ }^{[31]}$ showed for the P-SHPB used in this research work, nonlinear curves of perforation velocity $\left(v_{p}\right)$ and striker impact velocity $\left(v_{i}\right)$ versus compressor impact pressure (p) in Pascal are given as,

$$
v_{p}=9 \times 10^{-5} p^{0.7072}
$$

The speed of the striker rod is determined by compressor pressure. The strain wave pulse provides information for complete characterization of the damage process. 
Integrating this wave provides the energy absorbed-time history, force-displacement, stress-strain, and other relevant data with which the specimen damage can be characterized. For interested readers the detail of the experimental set up can be found in other published papers of the authors ${ }^{[27-31]}$. The corresponding perforation $\left(E_{p}\right)$ and impact energies $\left(E_{i}\right)$ are given by,

$$
E_{p}=\frac{1}{2} m_{p b} v_{p}^{2} \quad ; \quad E_{i}=\frac{1}{2} m_{s b} v_{i}^{2}
$$

Where the mass of the penetrating incident bar, $m_{p b}$, is $14.6 \mathrm{~kg}$ and the mass of the striker bar, $m_{s b}$, is $2.47 \mathrm{~kg}$. A protruding hemispherical nosed penetrator is mounted at the end of the incident bar is used.

The specimen is placed in a penetrator holder, which is mounted at the end of the incident bar. The setup is made such as to allow energy transfer from the incident bar through the specimen to the transmitter bar only via longitudinal waves. Precautions were taken to avoid dynamic movement of the bars and specimen with respect to each other and minimizing the friction effect and perturbation of the waves. Longer bar and shorter specimens were used to utilize the assumption of one dimensional stress waves travelling along the bars and specimen since the experiment fulfilled the ratio of diameter to length of bars condition in Kolsky bar experiments. The specimens are circular discs of diameter of $52 \mathrm{~mm}$ and thickness of $2.54 \mathrm{~mm}$ and 5.08 $\mathrm{mm}$. The specimens are made of toughened double directional woven graphite epoxy composites (WGEC), ferrite stainless steel cast 18-8, aluminum cast 195-76 and dry natural maple wood possessing multidirectional fiber cellulose. The strain gages are placed at the same distance from the specimen, i.e. at mid-point of the incident and transmitted bars. Table I is the list of the acceptable data captured by the oscilloscope and the strain gages.

TABLE I EXPERIMENTAL DATA RECORDING DURING EXPERIMENT

\begin{tabular}{cccccc}
\hline $\begin{array}{c}\text { Specimen } \\
\text { ID }\end{array}$ & $\begin{array}{c}\text { Thickness } \\
(\mathbf{m m})\end{array}$ & $\begin{array}{c}\text { Impact } \\
\text { Pressure(k Pa) }\end{array}$ & $\begin{array}{c}\text { Specimen } \\
\text { ID }\end{array}$ & $\begin{array}{c}\text { Thickness } \\
(\mathbf{m m})\end{array}$ & $\begin{array}{c}\text { Impact } \\
\text { Pressure (k Pa) }\end{array}$ \\
\hline GWE-92 & 2.54 & 117.21 & WD-20 & 2.54 & 82.74 \\
GWE-70 & 2.54 & 137.90 & WD-09 & 2.54 & 103.42 \\
GWE-64 & 2.54 & 158.58 & WD-17 & 2.54 & 172.37 \\
GWE-59 & 2.54 & 344.74 & WD-5 & 5.08 & 137.90 \\
GWE-03 & 5.08 & 158.58 & WD-6 & 5.08 & 172.37 \\
GWE-15 & 5.08 & 241.32 & WD-14 & 5.08 & 206.84 \\
GWE-4 & 5.08 & 303.37 & ST-5 & 5.08 & 482.63 \\
GWE-01 & 5.08 & 379.21 & ST-31 & 5.08 & 1241.06 \\
AL-8 & 2.54 & 413.69 & ST-16 & 2.54 & 689.48 \\
AL-13 & 2.54 & 517.11 & ST-19 & 2.54 & 827.37 \\
AL-27 & 5.08 & 599.84 & ST-33 & 2.54 & 896.32 \\
AL-26 & 5.08 & 620.53 & & & \\
\hline
\end{tabular}

The damage modes are categorized as indentation (Ind), penetration (Pen), perforation (Perf), punch-through (PT) and plugging by visual observation of the damage on the tested specimens. Indentation mode is when the penetrator makes visible damage on the contact surface of the specimen with no visible bulge on the other side. If the contact surface shows a visible damage and the other side has a visible bulge, the damage mode is partial penetration. Perforation damage on the specimen allows light through the opening caused by the impact or occurs when the penetrator-head just exits the rear surface of the specimen. Punch through is defined as when the penetrator-head passes through the specimen and creates a permanent hole. Fragmentation is a dynamic damage mode in which the 
material breaks into fragments before penetration occurs. This is shown to be the major damage mode for the wood, specimen since its fiber structure makes it harder to have perfect penetrations. A penetration, which causes a mass loss from the specimens by the perforation, is known as plugging. The surfaces of the specimen are lubricated before the test to reduce the effect of surface friction on the results. Factors leading to discarding the results of some of the tested specimens were no clear wave, no response on the oscilloscope and pressure drop before triggering the system and some other uncertainties. All data captured by the oscilloscope and the pressure transducer are recorded after each test.

\section{IV.FORMULATION OF THE PROBLEM}

The basic assumptions and validity of Split Hopkinson Pressure Bar (SHPB) in the study of the dynamic behavior of materials are well documented and summarized in [32]. These validation assumptions contain minimum dispersion, elastic conditions of the bars, homogeneous state of stress in the plate material, and non-dimensional uniaxial stress. For the P-SHPB, it is further assumed that sample strain is much greater than the total strain of the bar and the specimen fixture. Important assumptions for mathematical description of material deformation under dynamic impact are as follows ${ }^{[4,20] \text { : }}$

1. The composite plate is elastic and its properties remain unchanged by the impact.

2. The state of the stress over the cross sectional area is one-dimensional and uniaxial.

3. The wave is non-dispersive.

4. The state of the stress at any instant is homogenous and in equilibrium over the entire composite plate.

5. Transverse strain, lateral inertia, and body forces are all negligible.

Assumption (1) allows the use of elementary wave theory to describe wave propagation within the bars. Neglecting minor local heating of the specimen, the material properties will remain unchanged throughout the penetration process. If $d$ and $L$ are the diameter and length of the bar, respectively, Poisson's effect is negligible when the Poisson's ratio is small compared to unity. Elementary wave theory that neglects Poisson's effects are valid for the description of wave motion in a SHPB if the wavelength $(\lambda)$ of the propagating wave is ten times the diameter (d) of the bar ${ }^{[33]}$. In the present investigation, the wavelength of the incident pulse is $610 \mathrm{~mm}$ compared to $25.4 \mathrm{~mm}$ of the rod diameter. Thus, elementary wave theory is valid.

A one-dimensional uniaxial stress condition (assumption 2) is satisfied by making the bars prismatic and slender. Planar waves will remain planar and parallel to the cross section during propagation from one section to another. If $L$ is the bar length traveled by the wave, the condition of onedimensional planar state of the stress is satisfied if the slenderness ratio $\mathrm{d} / \mathrm{L}<1 / 50^{[34]}$. The current test apparatus has a slenderness ratio of $1 / 144$. Thus, deviations of the wave motion from a one-dimensional planar state are negligible.

Since the calculated axial stress in the specimen depends linearly on the axial strain on the transmitter bar, wave dispersion would result in underestimating the strength of the specimen. Assumption 3 is satisfied when the stress wave rise time (the time required for the stress to increase from $10 \%$ to $90 \%$ of its final value) is two or three times greater than the time required for the pulse to traverse the diameter of the $\operatorname{rod}^{[34]}$. For the current set-up, the rise time is $15 \mu$ s compared to $5 \mu$ s to traverse the diameter of the rod (three times greater), and therefore, Assumption 3 is satisfied.

The effect of non-uniform stress and non-equilibrium within the specimen used in this study is minimized by using longer bars and short specimen. Since the time to traverse the specimen is short compared to the duration of the wave, equilibration within the specimen is satisfied by the possible multiple reflections ${ }^{[21]}$. Thus, stress will be homogenous within the specimen, satisfying Assumption 4. Transverse strain, lateral inertia, and body forces are all negligible since the rise time condition is satisfied and the impact is normal to the longitudinal direction. Consequently, the uniaxial stress of the specimen, $\sigma$, may be calculated from the dynamic loading of composite plates at the incident bar generated by the longitudinal impact load $F_{0}$ of the striker bar as,

$$
\sigma(t)=\frac{F_{o}}{A_{b}}=\left(\begin{array}{ll}
\rho & c_{o}
\end{array}\right) v(t)
$$

where $c_{0}=d x / d t$ is the velocity of the wave pulse in the bar, $v(t)$ is the particle velocity, and $\rho$ is the density of the striker bar material. With a specimen of the cross sectional area, $A_{c}$, placed in a specimen fixture and sandwiched between the incident (input) and transmitter (output) bars of the cross section area, $A_{b}$. Equilibrium at each interface (input bar/penetrator, penetrator-head/specimen, specimen/fixture, and fixture/output bar) encountered is satisfied by the continuities of forces and velocities at the interface. The incident, reflected and transmitted strain waves are known from strain-gauge measurements on the input and output bars ${ }^{[10,11]}$. Since maximum stress is directly proportional to the maximum particle velocity, they are important experimentally and can be determined from recorded stress wave data. The next formulas give the sample's particles displacements, strain, and velocity at the interface of incident bar,

$$
\begin{gathered}
u(x, t)=u_{i}(x, t)+u_{r}(x, t)=f(x-c t)+g(x+c t) \\
\varepsilon(x, t)=\frac{\partial f(x, t)}{\partial x}+\frac{\partial g(x, t)}{\partial x}=\varepsilon_{i}(t)+\varepsilon_{r}(t)
\end{gathered}
$$




$$
v(x, t)=\dot{u}=\frac{\partial f(x, t)}{\partial t}+\frac{\partial g(x, t)}{\partial t}=-v_{i}(t)+v_{r}(t)
$$

Where, $f$ and $g$ are the displacement functions, and "i" and " $r$ " indices stand for incident and reflected waves at the interface, respectively. The specimen particle's velocity can be determined from the continuity condition of velocity and force equilibrium conditions at the specimen-bar interface,

$$
V_{s}=\frac{C_{o}}{E_{o}}\left(\sigma_{i}-\sigma_{r}\right)
$$

where $C_{o}$ and $E_{o}$ are the velocity of the wave in the Hopkinson bar and the young's modulus of the Hopkinson bar material. Then, load on the interface is,

$$
P_{1}=A_{b} E_{o}\left(\varepsilon_{i}(t)+\varepsilon_{r}(t)\right)
$$

The displacement in incident bar- specimen interface,

$$
u_{i}(x, t)=\int_{0}^{t}\left(-v_{i}(t)+v_{r}(t)\right) d t
$$

Similarly, on the displacement, particle's strain and velocity at the transmitter bar interface are given using the displacement function $h$, respectively,

$$
\begin{aligned}
& u(x, t)=u_{i}(x, t)=h(x+c t) \\
& \varepsilon(t)=\frac{\partial h(x, t)}{\partial x}=\varepsilon_{t}(t) \\
& v(t)=\dot{u}(t)=\frac{\partial h(x, t)}{\partial x}=v_{t}(t)
\end{aligned}
$$

Load on the interface of the specimen with transmitter bar is,

$$
P_{2}=A_{b} E_{o} \varepsilon_{t}
$$

The displacement of the transmitter bar-specimen interface is,

$$
u_{2}(x, t)=\int_{0}^{t} v_{t}(t) d t
$$

For a uniform stress through a thin specimen, the loads on the interfaces are assumed equal $\left(P_{1}=P_{2}\right)$ and $\varepsilon_{i}+\varepsilon_{r}=\varepsilon_{t}$ and the average sample stress, $\bar{\sigma}_{s}(t)$, strain, and strain rate can respectively be defined as,

$$
\begin{aligned}
& \bar{\sigma}_{s}(t)=\frac{P_{1}+P_{2}}{2 A_{c}} \approx \frac{A_{b}}{A_{c}} E_{O} \varepsilon_{t}(t) \\
& \bar{\sigma}_{s}(t)=\frac{u_{2}+u_{1}}{L_{e}} \approx \frac{-2 c_{0}}{L_{e}} \int_{0}^{t} \varepsilon_{r}(t) d t
\end{aligned}
$$

$$
\dot{\varepsilon}_{r}(t) \approx \frac{-2 c_{0}}{L_{e}} \varepsilon_{r}(t)
$$

$L_{e}$ is the effective length between the bar ends taken to be equal to the thickness of the specimen when the specimen strain is much greater than the strain in the bar fixture and penetrator head. The uniaxial waveform generated in the bar determines the rate at which energy is transferred from the bar to the specimen.

Assuming that the energy delivered by the incident bar and penetrator is equal to the total expendable energy $\left(E_{A}\right)$ for the penetration process, the energy transferred by the propagating compressive wave to the composite plate $\left(\mathrm{E}_{\mathrm{p}}\right)$ is derived using the net plate deformation, $d \delta_{\mathrm{n}}$, as,

$$
d E_{p}(t)=F_{i}(t) d \delta_{n} \equiv E_{A}(t)
$$

Hence,

$$
E_{p}(t)=\int_{0}^{t} F_{i}(t) d u_{n} \equiv E_{A}(t)
$$

where

$F_{i}(t)=A_{b}\left(\sigma_{i}(t)+\sigma_{r}(t)\right)=A_{s} \sigma_{t}(t)=F_{s}(t)$ is the net compressive loading force and the net plate displacement $d u_{\mathrm{n}}$ is simplified to become,

$$
d u_{n}(t)=\frac{C_{o}}{E_{o}} \int_{0}^{t}\left[\sigma_{i}(t)-\sigma_{r}(t)-\sigma_{t}(t)\right] d t
$$

Since $\varepsilon_{s}(t)=\frac{u_{n}(t)}{L_{e}}$, therefore, the total specimen strain is,

$$
\varepsilon_{s}(t)=\frac{C_{o}}{L_{e}} \int_{0}^{t}\left[\varepsilon_{i}(t)-\varepsilon_{r}(t)-\varepsilon_{t}(t)\right] d t
$$

$E_{p}$ can be obtained as the integrated area of the forcedisplacement curve over the duration of the wave. Substituting $d_{n}$ and $F_{i}(t)$ expressions into Eq-20, the net energy to be expended for the damage generation process plus energy losses to the fixture is expressed as,

$$
E_{A}(t)=\frac{A C_{o}}{E_{o}} \int_{0}^{t}\left[\sigma_{i}^{2}(t)-\sigma_{r}^{2}(t)-\sigma_{t}^{2}(t)\right] d t
$$

Thus, Eq-23 gives the total energy absorption curve decomposed into energy absorbed by the plate $\left(\Delta E_{a b s}\right)$ and the elastic strain energy $\left(\Delta E_{s}\right)$, i.e.,

$$
\begin{aligned}
& E_{A}^{\min }=\Delta E_{a b s} ; \\
& E_{A}^{\min }=\Delta E_{a b s}+\Delta E_{s}
\end{aligned}
$$


The total energy absorption curve can be decomposed into energy absorbed by the elastic strain energy $\left(E_{s}\right)$ and the specimen ( $\left.E_{a b s}\right)$ which may cause fracture in the specimen. Therefore the range of the $E_{A}(t)$ is,

$$
\Delta E_{s} \leq E_{A} \leq \Delta E_{a b s}+\Delta E_{s}
$$

The validly of the proposed P-SHPB method can be justified since only the strain measurements on the input and output bars and the geometry of the bars and specimen are required for the determination of particle velocities, displacements and energy absorption. The drawback in the continuity assumption, however, is that energy losses to the specimen fixture and the penetrator head could reduce the relative strain reaching the gage at the mid-point of the output bar. This will result in over-estimating the energy measurement by Eq-23. An experimentally determined correction factor that accounts for the total energy loss to the penetrator and fixture are usually applied to minimize the error due to the losses. Although the error could reduce the accuracy of PSHPB method for absolute measurements of materials properties, P-SHPB remains a reliable tool for elaborating the penetration/perforation mechanics and dynamic failure behaviors of composite materials subjected to high strain rate loading.

\section{RESULTS AND DISCUSSIONS}

Experimental results of specimens in Table 1 are grouped based on the similar material, geometrical dimension, striker bar's impact pressures and produced damage mode. The crack size on the specimen, the maximum damage height (distance between the original impact side to the tip of bulge of material) on the exit opposite side and the observed damage type of specimen are recorded as crack length, crack height and damage mode in Table II, respectively. The applied pressure to initiate a dynamic failure mode in Table 1 is converted to striker impact energy using Eq-3. The minimum striker impact energy to initiate a typical damage mode is the threshold energy corresponding to that damage mode. It is understandable from the applied pressure in Table 1 and dynamic failure recorded in Table 2 for each tested disk, that finding the threshold of applied energy to produce specific damage mode is a challenge in the experiments. The images in the Fig. 3 show different modes in the tested samples of aluminum, steel, woven composites, and wood. The numerical integration is carried out with time shifted to zero and all three waves (incident, transmitted and reflected) beginning at the same time and for the same time duration, $t$, for stress analysis. Fig. 4 is the incident (compressive) and reflected (tensile) stress waves captured by the oscilloscope. It can be seen in Fig. 4 that the compression and tension stress waves for GWE-24-04 travelling within the specimen's thickness have almost the same amplitude. Fig. 4 shows a series of incident (compressive) and reflected (tensile) wave stresses, in which after multiple reflections in the specimen reach to a state of stress equilibrium. Hence it is adequately within acceptable estimation to use the first compression-tension stress wave set for evaluate the damage process by comparing the first incident stress waves with the corresponding transmitting and reflecting waves.

TABLE II CHARACTERISTICS DATA OF THE EXPERIMENTS DEMONSTRATING SIX DAMAGE MODE: (1) INDENTATION (IND) ; (2) PENETRATION (PEN); (3) PERFORATION (PERF); (4) PUNCH-THROUGH (PT); (5) FRAGMENTATION (FRAG); (6) PLUGGING (PLUG)

\begin{tabular}{|c|c|c|c|c|c|c|c|}
\hline $\begin{array}{l}\text { Specimen } \\
\text { ID }\end{array}$ & $\begin{array}{c}\text { Height } \\
\text { of crack } \\
\text { (mm) }\end{array}$ & $\begin{array}{c}\text { Crack } \\
\text { length } \\
(\mathrm{mm})\end{array}$ & $\begin{array}{c}\text { Damage } \\
\text { Mode }\end{array}$ & $\begin{array}{c}\text { Specimen } \\
\text { ID }\end{array}$ & $\begin{array}{c}\text { Height } \\
\text { of crack } \\
\text { (mm) }\end{array}$ & $\begin{array}{c}\text { Crack } \\
\text { length } \\
(\mathrm{mm})\end{array}$ & $\begin{array}{l}\text { Damage } \\
\text { Mode }\end{array}$ \\
\hline GWE-12-92 & - & - & Ind & AL-24-27 & 7.112 & 7.112 & Perf \\
\hline GWE-12-70 & 3.556 & 4.064 & Pen & AL-24-26 & 6.35 & 6.35 & Plug \\
\hline GWE-12-64 & 6.604 & 10.16 & Perf & WD-12-20 & - & - & Ind \\
\hline GWE-12-59 & 8.128 & 14.478 & PT & WD-12-09 & - & - & Frag (2 pcs) \\
\hline GWE-12-03 & - & - & Ind & WD-12-17 & - & - & Frag (4 pcs) \\
\hline GWE-24-15 & - & - & Pen & WD-24-5 & - & - & Frag (3 pcs) \\
\hline GWE-24-04 & 8.89 & 8.89 & Perf & WD-24-6 & - & - & Frag (4 pcs) \\
\hline GWE-24-01 & 9.652 & 12.954 & PT & WD-24-14 & - & - & Frag (5 pcs) \\
\hline AL-12-8 & 3.556 & 4.064 & Pen & ST-24-5 & - & - & Ind \\
\hline AL-12-13 & 5.08 & 5.588 & Pen & ST-24-31 & 7.366 & 7.112 & Pen \\
\hline
\end{tabular}




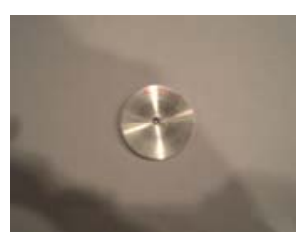

Aluminum 1:

Indentation

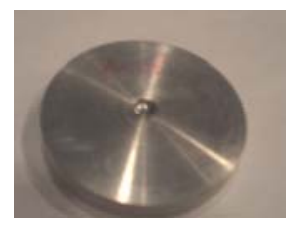

Steel 1: Indentation

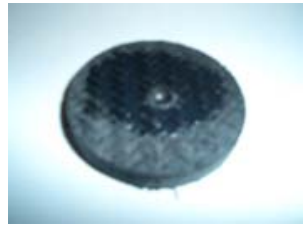

Woven 1: Indentation

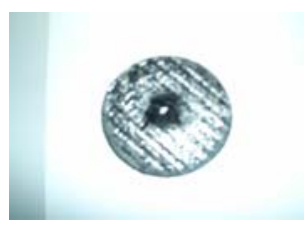

Woven 4: Punch Through

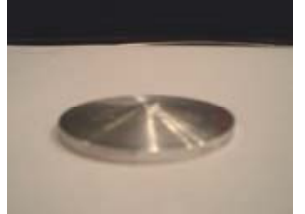

Aluminum 2:

Penetration

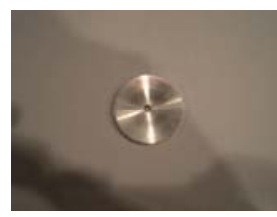

Steel 2: Penetration

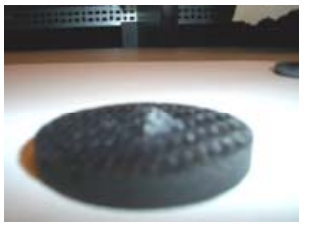

Woven 2: Penetration

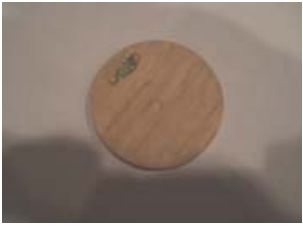

Wood 1: Indentation

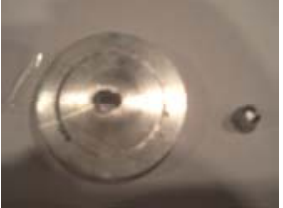

Aluminum 3:

Plugging

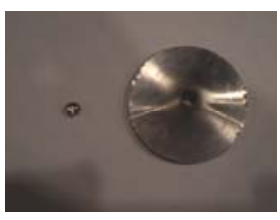

Steel 3: Plugging

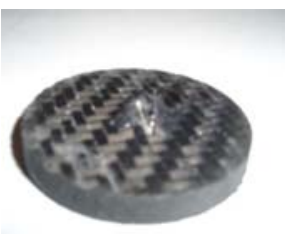

Woven 3: Perforation

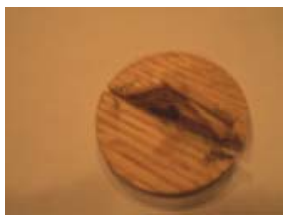

Wood 2: Fragmentation

Fig. 3 Images of different damage modes in the tested samples of aluminum, steel, woven composites, and wood

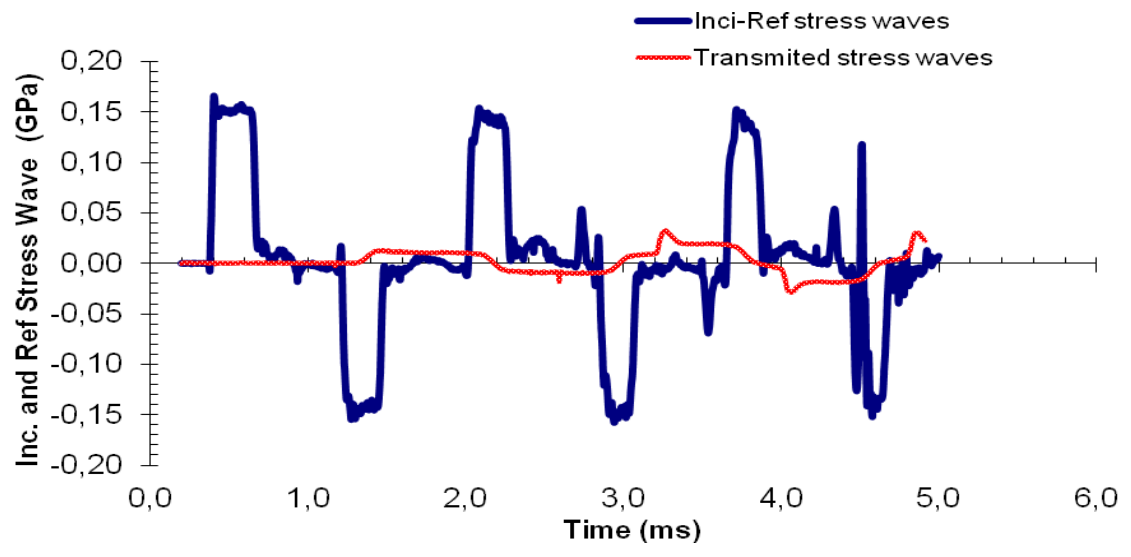

Fig. 4 Incident and reflected stress waves on the bar captured by the oscilloscope

The theoretical formulation for the P-SHPB or fracturing split Hopkinson pressure bar (F-SHPB) of Fig. 1 is based on the classical wave propagation through interfaces similar to the conventional SHPB (see Figures 1), for which the specimen is sandwiched between an incident input and transmitter output bar. The set up for a P-SHPB system in 
Fig. 2 shows that the attachments of the penetrator (indentor) head to the input bar and the specimen fixture to the output bar introduce additional boundaries and interfaces to the system. The fact that the specimen in the specimen fixture is not in direct contact with the transmitter bar further complicates the wave propagation and causes the assumptions on equilibrium and continuity not to be fully achieved in the P-SHBP tests. For the conventional SHPB system, the state of stress is only slightly off from equilibrium by less than $10 \%$. However, for penetration or fracture tests from the P-SHBP or the F-SHPB set up, the stress equilibrium is significantly off from equilibrium due to attenuations via the interfaces introduced to the system by penetrator and specimen fixtures. The effect is very much pronounced in the transmitted wave, resulting in deviation from equilibrium as much as $300 \%$ if not accounted for. Analytical equations for the P-SHPB system can be approximated to consider the effect of presenting the indentor and the specimen holder in the system, and the consequence deviation from equilibrium accounted for, with appropriate corrections of the SHPB formulations. The deviation from equilibrium state or P-SHPB transmitted wave from the conventional SHPB can be accounted for by an experimentally determined correction factor such that,

$$
\varepsilon_{t c}(t)=\left[C_{P t}(t)\right] \varepsilon_{t m}(t)
$$

where $\varepsilon_{\mathrm{tm}}(\mathrm{t})$ and $\varepsilon_{\mathrm{tc}}(\mathrm{t})$ are the measured attenuated transmitted strain pulse and the corrected transmitted strain pulse for the P-SHPB set up, respectively. Hence, $\mathrm{C}_{\mathrm{Pt}}(\mathrm{t})$ is an experimentally determined correction factor that normalizes strain measurements in P-SHPB with respect to the strain in the conventional SHPB. To determine $\mathrm{C}_{\mathrm{Pt}}(\mathrm{t})$, a sample of smooth surface is placed between the bars as in Fig. 2 SHPB set up and the strain wave imposed to the tested plate by the striker bar impact energy, is measured without the penetrator and sample fixture attached to the incident and transmitter bars, respectively. Then, the measurement is repeated at the same conditions but using the P-SHPB set up in which the penetrator is attached to the input bar and the sample fixture with the sample inside is attached to the output (transmitter) bar. The striker bar impact energy is chosen below the damage energy threshold of the specimen's perforation. The factor $\mathrm{C}_{\mathrm{Pt}}(\mathrm{t})$ is determined as a non-linear time dependent ratio of the transmitted strain wave $\left(\varepsilon_{S H P B}^{t}(t)\right)$ measured in SHPB set up to strain wave $\left(\varepsilon_{P-S H P B}^{t}(t)\right)$ in P-SHPB set up and is given as,

$$
C_{P t}(t)=\frac{\varepsilon_{S H P B}^{t}(t)}{\varepsilon_{P-S H P B}^{t}(t)}
$$

Fig. 5 shows the time dependent graph of $\mathrm{C}_{\mathrm{Pt}}(\mathrm{t})$ and the plot of $\varepsilon_{S H P B}^{t}(t)$ versus $\varepsilon_{P-S H P B}^{t}(t)$ strain pulses measured from the stain gages (knowing one volt is equal to 833 micro-strain). The result indicates a significant difference due to attenuation of the P-SHPB wave. $\mathrm{C}_{\mathrm{Pt}}(\mathrm{t})$ is observed to peak after 150 microseconds before decreasing to zero. A forth degree polynomial curve fitting gives a good correlation $(r=0.93$ fit to the experimental data. Fig. $5 \mathrm{~b}$ also shows a good correlation $(\mathrm{r}=0.94)$ between the SHPB transmitted strain and the P-SHPB strain waves. Comparison the corrected strain wave with the conventional measurements in Fig. 5 shows a close match between the two graphs (the solid line in Fig. 5a is for SHPB measurement). Considering the hypothesis determined experimental set up, compliance factor can be used to correct for deviations between the P-SHPB and the conventional set up. Fig. $5 \mathrm{~b}$ is an example of compressive stress waves of steel specimen with thickness of $5.08 \mathrm{~mm}$ for P-SHPB without and with compliance penetrator-sample holder compliance correction factor $\left(\mathrm{C}_{\mathrm{pt}}(\mathrm{t})\right)$. The correlation factor reduces the deviation to less than $15 \%$ due to other frictional losses not accounted for. In the case of onedimensional stress waves presented here, the major effect of the penetrator head-sample holder fixture is to underestimate the absolute mechanical properties such as the elastic modulus and yield strength of the tested materials when Eq-16 is used to obtain the sample stress. However, the penetrator-sample holder does not affect the general conclusions on the mechanical behavior of the material from the experiments. The sample strain, sample stress and energy absorbed can be approximated within the deviation range of the experimental values of $\mathrm{C}_{\mathrm{pt}}(\mathrm{t})$. Similar measurement can be done using the appropriate F-SHPB fracture test setup, specimen fractor, and sample fixture, to determine $\mathrm{C}_{\mathrm{Ft}}(\mathrm{t})$. The modified transmitted stress wave is given as,

$$
\sigma_{t c}(t)=E_{o} \varepsilon_{t c}(t)=E_{o}\left[C_{P c}(t)\right] \varepsilon_{t m}(t)
$$

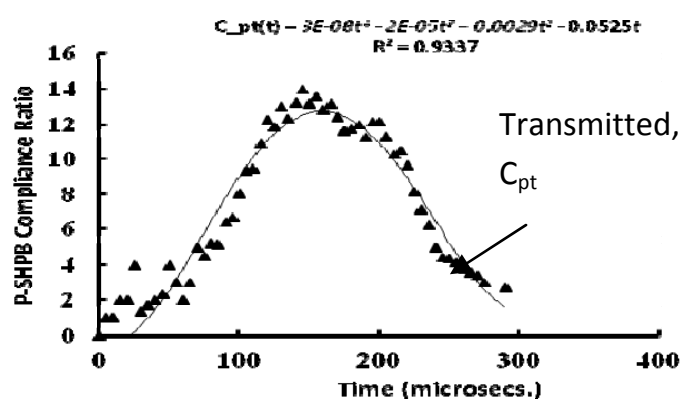

(a)

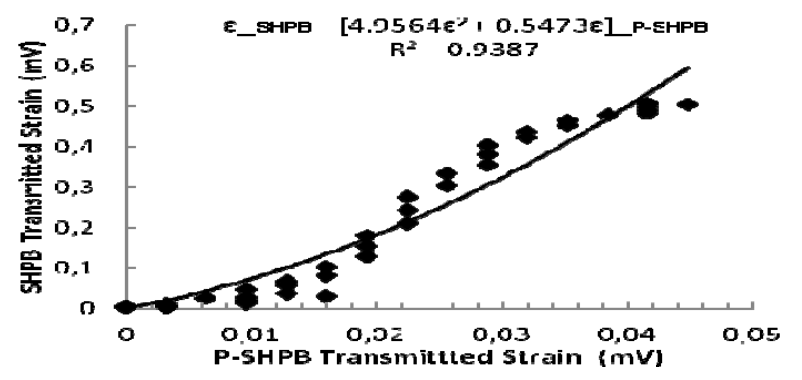

(b)

Fig. 5 (a) Time variation of P-SHPB Compliance ratio and (b) correlation of SHPB and P-SHPB transmitted strain wave for the first 200 microseconds 
Thus, equations for the P-SPHB or F-SPHB system are approximated from the conventional SHPB by replacing $\sigma_{t}$ (t) in SHPB by $\sigma_{t c}(t)$ obtained from Eq-28. The same correlation must be applied to the reflected stress waves and replace $\sigma_{\mathrm{r}}(\mathrm{t})$ in SHPB by $\sigma_{\mathrm{rc}}(\mathrm{t})$ for P-SPHB or F-SPHB system to minimize the error in the stress analysis. This correction significantly reduces the deviation from stress equilibrium to less than $25 \%$ and recommended when absolute measurements of materials properties are the end goals. The deviation from equilibrium and attenuation due to the introduction of the penetrator and sample fixture remains a major concern and the authors recognize the need to research and develop a complete dynamic formulation that accounts for all the interface boundaries, inertial and friction effects for the P-SHPB and F-SHPB systems.

Fig. 6 is the calibrated compressive stress waves for the impact wave of a woven graphite epoxy specimen with 5.08 $\mathrm{mm}$ thickness. The incident stress wave, after initial maximum, reaches to an average of $0.15 \mathrm{GPa}$. The reflected stress wave has a maximum value approximately equal to the average incident stress wave at impact instant, but its amplitude diminishes to zero for the rest of the pulse period. The graph for the transmitted stress wave shows a delay in beginning of the transmitting impact stress but it transfers the energy from the output face of the disk to the transmitter bar more with declining the reflected waves, showing a maximum point in the middle of the incident stress wave period. The transmitted wave is attenuated due to losses in the sample fixture and penetrators head, therefore, that is why, its maximum may not reach to the average of incident wave. Fig. 7 presents the effect of particle's velocity in the penetration depth, which results in one of the predefined deformation mode in the specimen. It can be seen from Fig. 7 that doubling the particle velocity from $4 \mathrm{~m} / \mathrm{s}$ to $8 \mathrm{~m} / \mathrm{s}$ increases the through the thickness penetration by six folds in case of the graphite epoxy specimens with $5.08 \mathrm{~mm}$ thickness. A direct relationship was observed between particle's velocity and the deformation of the sample by examining the similar graphs for other specimens. Fig. 8, shows higher strain rates for the high-energy events, and implies that the higher the damage threshold energy, the higher the strain rate, and therefore, the deeper the penetration in the specimen and deformation of the sample.

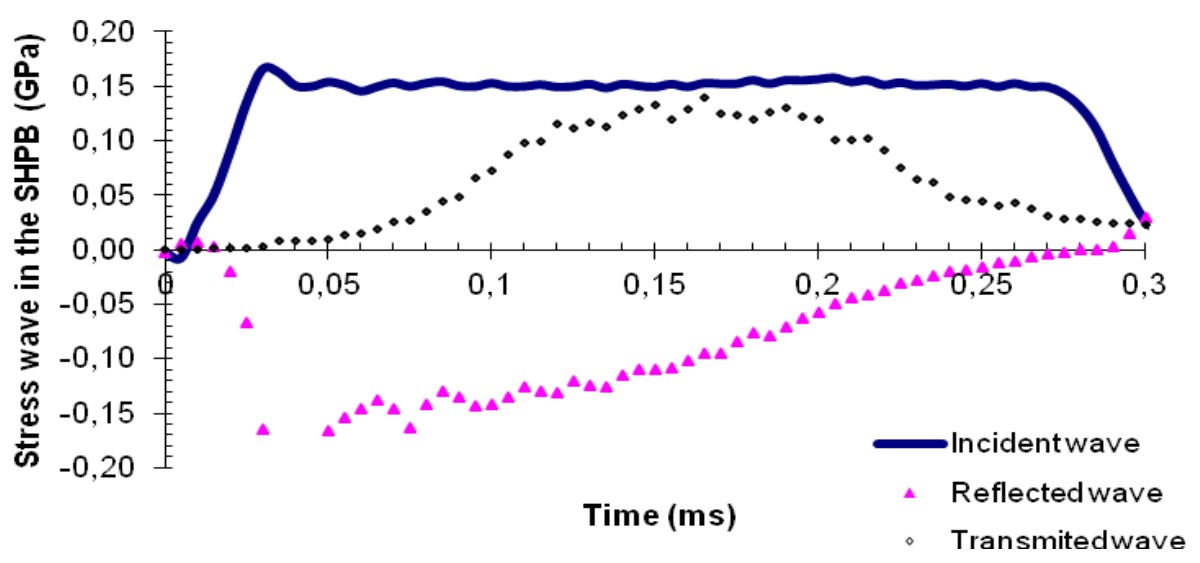

Figure 6 The calibrated incident, reflected and transmitted waves for "gwe-24-04" specimen

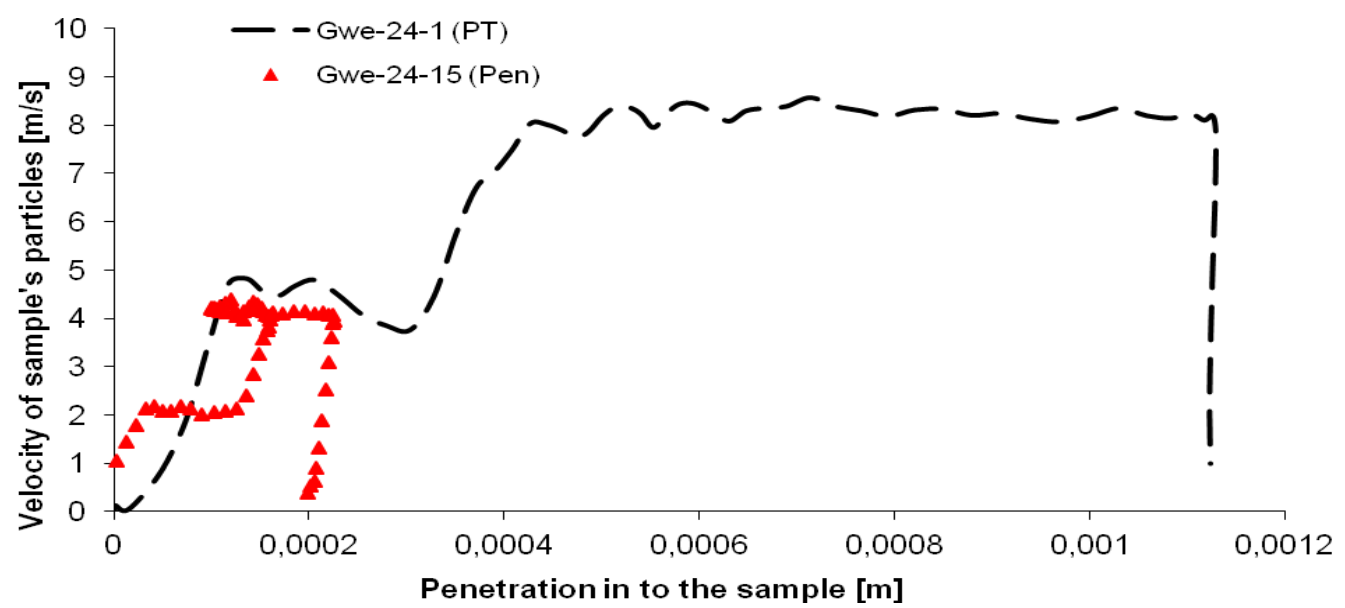

Fig. 7 Penetration (deformation) amount into the woven specimen with thickness $5.08 \mathrm{~mm}$ versus velocity 


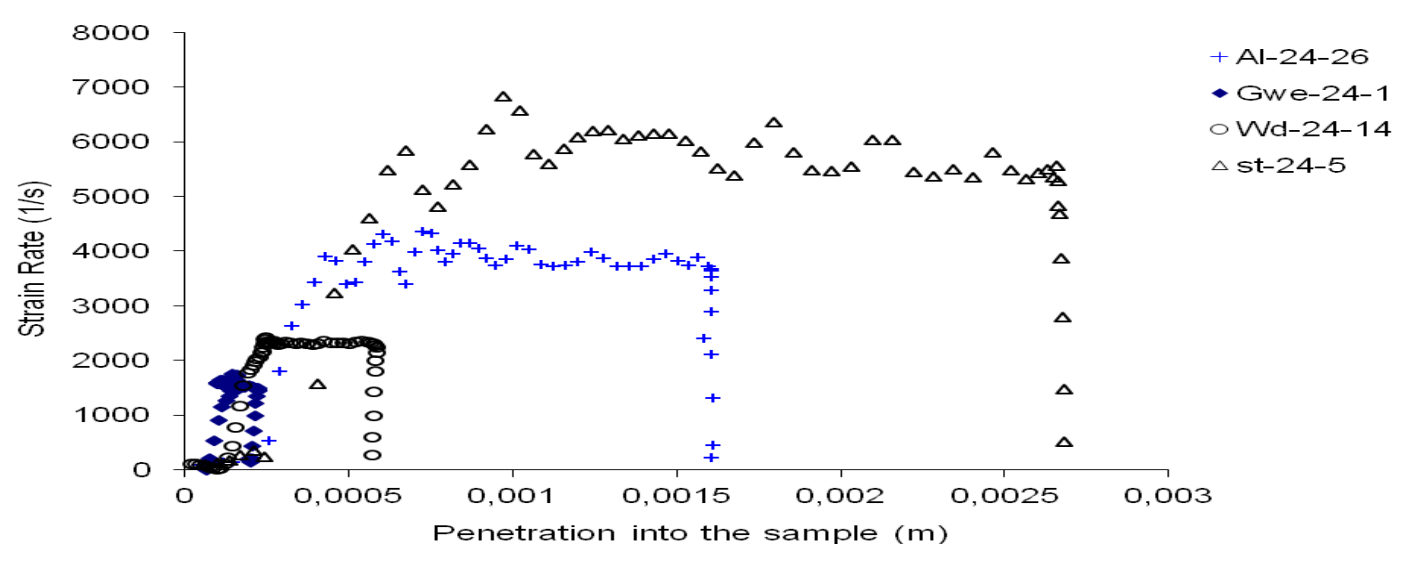

Fig. 8 Comparison of effect of sample particles' strain rate on penetration in the sample for wood, steel, aluminum and woven graphite epoxy specimen with thickness $5.08 \mathrm{~mm}$

Figures 9 and 10 show the energy absorption-time history for the specimens tested for the two thicknesses of 5.08 and $2.54 \mathrm{~mm}$ for fiber and metal material structures, respectively. Based on the energy absorptiontime history of the specimen, four critical energy levels, defined as yield energy (YE), ultimate energy (UE), strain-release energy (SE), and residual energy (RE), are absorbed during the first $300 \mu$ s of deformation time. Yield energy is the energy just before the slope of the stress-strain graph changes. Ultimate energy is the maximum energy or the peak energy available for the damage process. The strain (relaxing) energy is the first release of absorbed energy by the specimen characterized by force reversal at the rear tensile surface of the specimen and can be determined as the difference between UE and RE. The residual energy absorbed is the energy at the end of the strain energy released after the $300 \mu$ s deformation time.

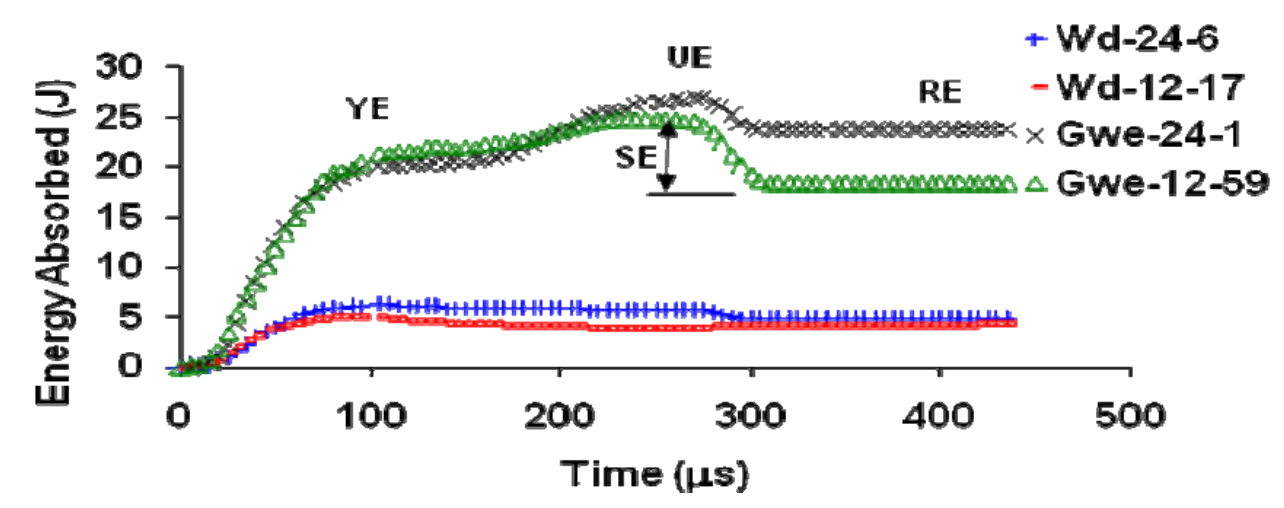

Fig. 9 Energy absorbed by the fiber structure during the impact test: (a) Wood $t=5.08 \mathrm{~mm}$ (b) Wood $\mathrm{t}=2.54 \mathrm{~mm}$ (c) WGEC $\mathrm{t}=5.08 \mathrm{~mm}$ (d) WGEC $\mathrm{t}=2.54 \mathrm{~mm}$

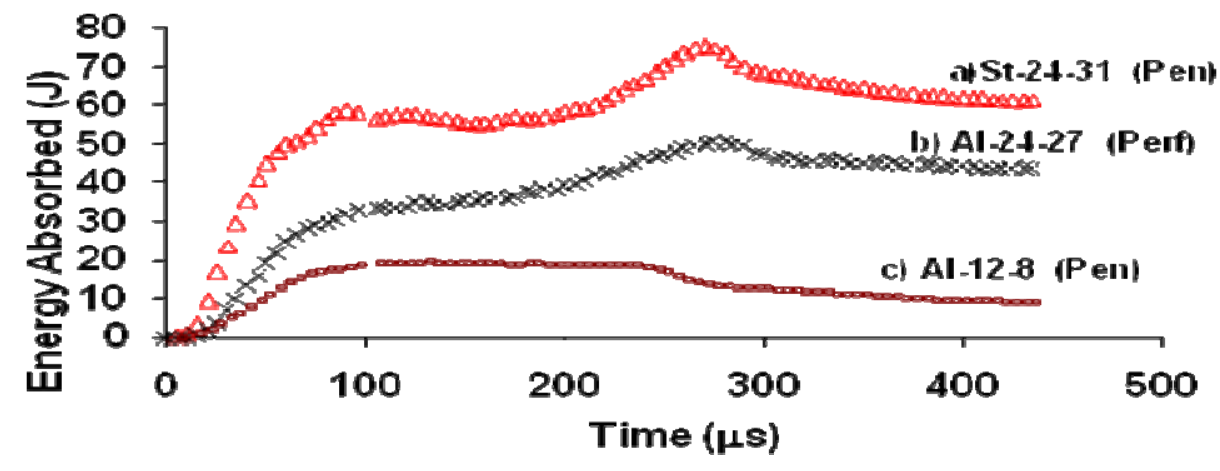

Fig. 10 Energy absorbed by the metal structure during the impact test: (a) Steel $t=5.08 \mathrm{~mm}$ (b) Steel $\mathrm{t}=2.54 \mathrm{~mm}$ (c) Aluminum $\mathrm{t}=5.08 \mathrm{~mm}$ (d) Aluminum $\mathrm{t}=2.54 \mathrm{~mm}$ 
Absorbed energy in the specimen after the relaxing stage is material dependent along other competing factors such as specimen fiber structure. It appears that the effect of thickness in absorbing energy is not the same for materials of different atomic structure, while the amount of the absorbed energy has a direct relationship with material structure. The energy absorbed in the aluminum increases from $18.2 \mathrm{~J}$ to $50.5 \mathrm{~J}$ by increasing the thickness of the aluminum sample from $2.54 \mathrm{~mm}$ to $5.08 \mathrm{~mm}$ in the case of the penetration mode, which demonstrates the effect of thickness on the energy absorption of an aluminum sample. In addition, from Fig. 10, it is revealed that as ductility of the material increases, the material becomes less capable to store energy in itself, since the consumed energy is used for the deformation of the specimen. Therefore, aluminum with higher ductility and FCC atomic arrangement shows lower values in the graphs in all critical energies compared to that of ferritic steel with BCC microstructure. The fiber structure is not affected much by increasing the thickness for the same type of failure. This fact can be seen for all four characteristic energies in the graphs. Both the woven composite and wood have a fiber structure, but woven composite has its layers over each other in different directions, while wood's layers coincide over each other. Multidirectional natural fiber structure of wood despite the higher density of fibers and existing natural adhesion between them compared to fabricated fibers in woven composite shows a much lower level of stored energy in undergoing the same dynamic failure. It may be the reason for catastrophic damage in wood by fragmentation rather than other damage modes such as plugging and penetration in this set of experiments on wood. This may indicate that the texture of the fibers can enhance the mechanical property of material, despite different sets of experiments is essential to confirm this more evidently.

The large difference in absorbed energy between metallic structure and fiber structure is due to delamination in the fiber structure, which causes much less absorption in the fiber structure material with the same geometrical dimension as metallic ones for the same damage mode. The strains with two different thicknesses of aluminum, wood, steel, and woven composite graphite are plotted in Fig. 11. Higher strain in thinner plates can be observed for all four materials. For both thicknesses of the specimen plates, an increase of $40 \%$ strain in steel is required to introduce penetration in the steel specimen compared to perforation in the aluminum specimen. Comparison of strain level for fragmentation in wood and punch through in WGEC with each other and damage level in aluminum and steel for both thicknesses of the specimens leads one to deduce that as the ability of material in absorbing energy increases, the deformation decreases. It is true in comparing metallic and fiber structural material with each other or metallic with a fiber structure specimen. It can be noticed from Fig. 11 that doubling the thickness of the specimen (Gwe-12 to Gwe-24, $\mathrm{Wd}-12$ to $\mathrm{Wd}-24$, and $\mathrm{Al}-12$ to Al-24) results in $50 \%, 50 \%$ and $25 \%$ reductions in sample strain for composite, wood and aluminum, respectively.
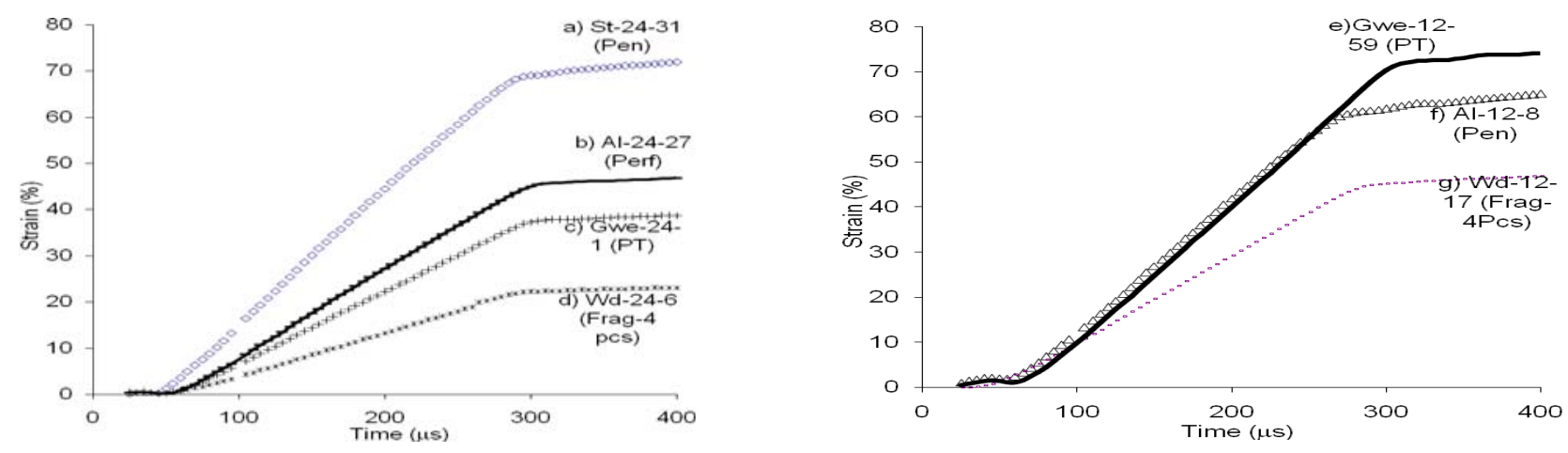

Fig. 11 Strain in the plate specimens of different material with different thickness ( $t$ ) as result of high energy impact; (a) Steel $t=5.08$ mm, (b) Aluminum $\mathrm{t}=5.08 \mathrm{~mm}$, (c) WGEC $\mathrm{t}=5.08 \mathrm{~mm}$ (d) Wood $\mathrm{t}=5.08 \mathrm{~mm}$, (e)WGEC $\mathrm{t}=2.54 \mathrm{~mm}$, (f) Aluminum $\mathrm{t}=2.54 \mathrm{~mm}$, (g) Wood $\mathrm{t}=5$

Figures 9, 10 and 11 show that the materials reach the peak absorbed energy before reaching maximum strain (maximum deformation) in the specimen, at about $300 \mu \mathrm{s}$. This is because the strain in the material is a function of absorbed energy by the material. Fig. 12 shows a range between 950 and $3500 \mathrm{~s}^{-1}$ for the sample strain rate in the tests. Three regions can be observed in the plots in Fig. 12: (i) sharp increase of strain rate at the first short time interval of the test, (ii) constant strain rate region at ultimate level and (iii) graduate decrease in strain rate. The first short time interval (less than 50 $\mu \mathrm{s})$ is related to elastic stress distribution in the specimens. The nature of the SHPB method prevents the determination of elastic properties of the material within this region because of stress wave reflection, stress nonuniformity and large variation in strain rate during the initial portion of the test ${ }^{[24]}$. Flow of stress plastically through a specimen generates a high strain rate in the impact test for the first $300 \mu$ s time interval. The strain rate reaches and remains at its ultimate limit for the wave duration time before the strain hardening of the material lowers the strain rate. 


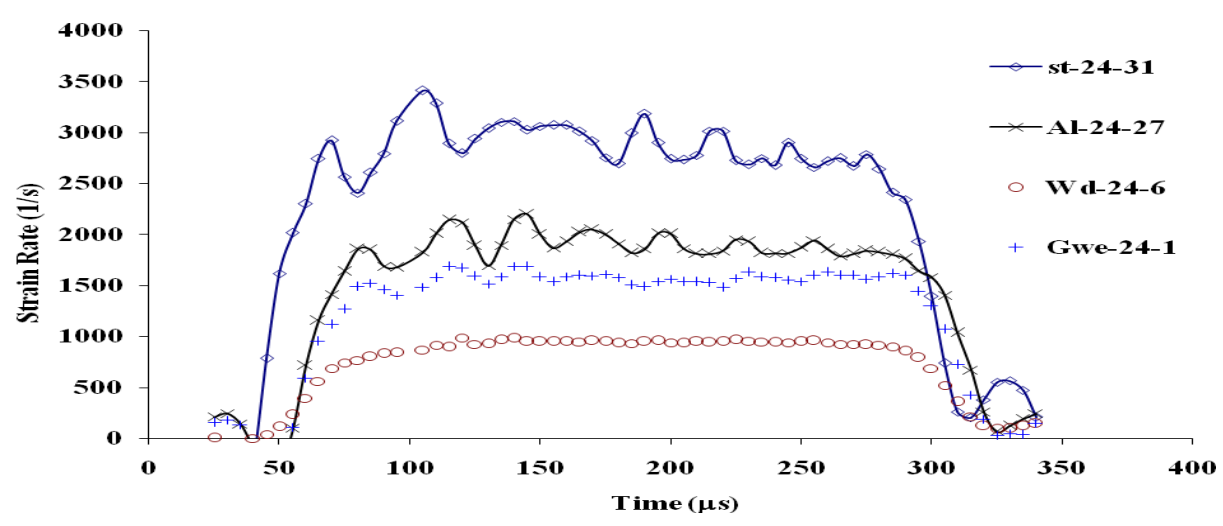

Fig. 12 Stress- rate relationship for steel, aluminum, wood and woven graphite epoxy composite with thicknesses $\mathrm{t}=5.08 \mathrm{~mm}$

Figures 13 (a) and (b) show the stress-strain relationships for all four materials for the two different thicknesses. Fig. 13 (a) shows that ultimate stress for the aluminum specimen, with $\mathrm{t}=2.54 \mathrm{~mm}$ and $5.08 \mathrm{~mm}$, are 10 $\mathrm{MPa}$ and $23 \mathrm{MPa}$ and yield stresses are $4 \mathrm{MPa}$ and $8 \mathrm{MPa}$, respectively. It also shows that for the relatively same level of the applied pressure $(517 \mathrm{kPa}$ for aluminum sample with $\mathrm{t}=2.54 \mathrm{~mm}$ and $599 \mathrm{kPa}$ for aluminum sample of $\mathrm{t}=5.08 \mathrm{~mm}$ ) the yield strain increases from $25 \%$ in the sample with thickness of $5.08 \mathrm{~mm}$, to $80 \%$ in the sample with thickness of $2.54 \mathrm{~mm}$. This fact shows a noticeable softening behavior in the thinner sample. The presence of the increased oscillations in Fig. 13 (b) shows the non-linearity and inelastic behavior of deformation in the wood samples. Fig. 13 (b) demonstrates that the woven composite with thickness of $5.08 \mathrm{~mm}$ has ultimate stress three times higher than wood with the same thickness which it shows a higher compressive strength compare to wood. The smooth curve of the woven specimens is due to its elastic character. The stress peaks or pulsation in the wood and woven composite material presents the characteristics of stress-strain relationship for the fiber structure materials.

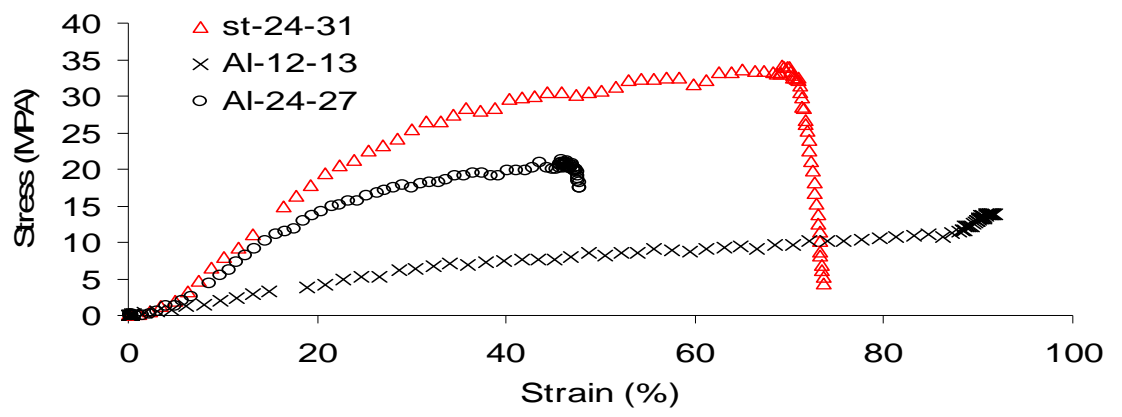

(a) Aluminum and steel specimens

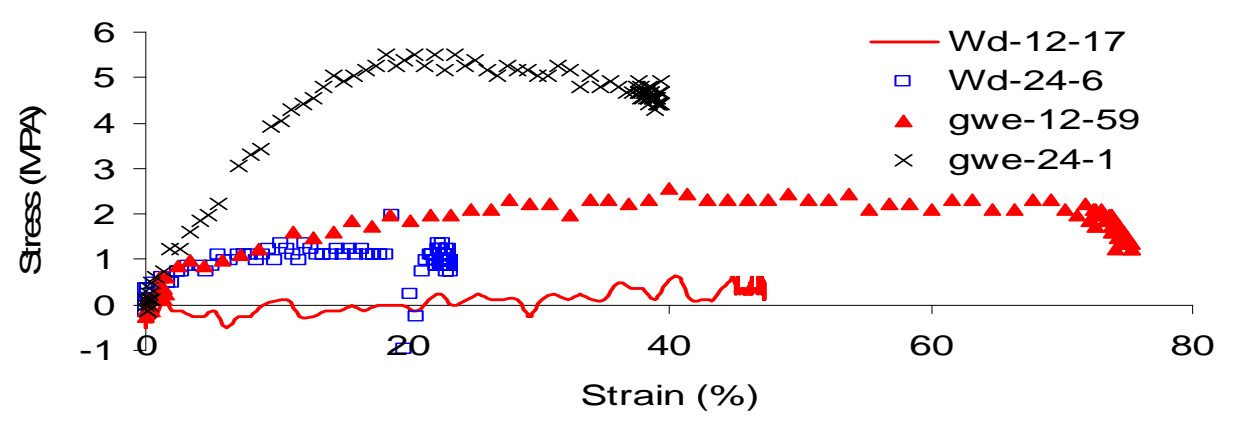

(b) Wood and WGEC specimens

Fig. 13 Stress- strain relationship for steel, wood and woven graphite epoxy composite with thicknesses $\mathrm{t}=2.54,5.08 \mathrm{~mm}$. 
It can be deduced that the deformation in the specimens is increased as the specimen's ultimate energy absorbed gets larger, which results in more catastrophic damage in high strain rate plastic deformation. The dependency of deformation on energy absorption follows a power law for the woven composite and approximate linear relationships for wood, aluminum, and steel. This is due to the anisotropic and heterogeneous nature of composite materials. However, more energy is absorbed in steel and aluminum than in composite in case of the same deformation mode (e.g. penetration, perforation, or punch-through).

The relation between energy absorbed and damage mode for all specimens in Fig. 14 gives good evidence that the deformation in the specimens is increased as the specimen's ultimate energy absorbed gets larger which results in more
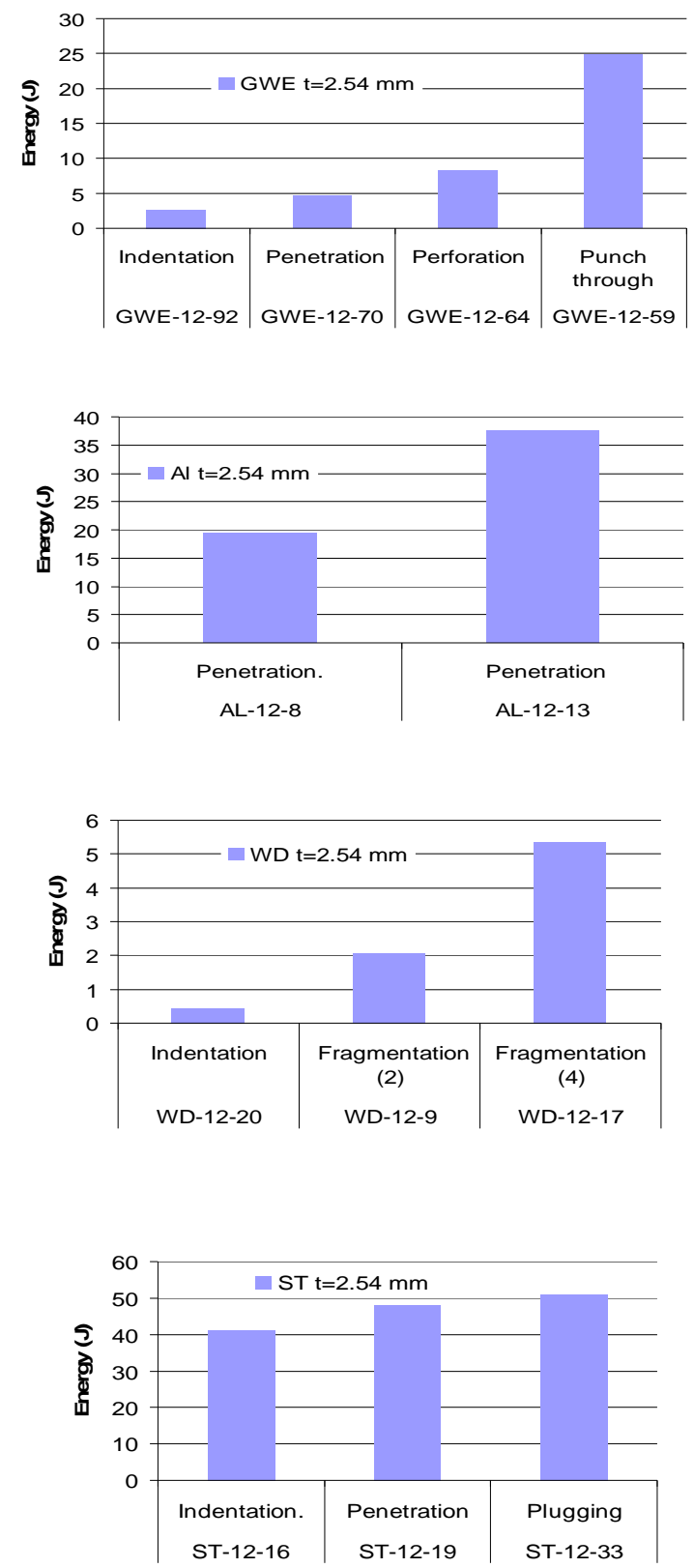

catastrophic damage in high strain rate plastic deformation. The results demonstrate that absorbed energy is a good characteristic parameter to predict the damage. The dependency of deformation on energy absorption follows a power law for the woven composite and approximate linear relationships for wood, aluminum and steel. This is due to the anisotropic and heterogeneous nature of composite materials. However, more energy is absorbed in steel and aluminum to cause the same deformation mode (penetration, perforation or punch-through) than in composite. Same conclusion can be made from Fig. 15 for dynamic failure modes under different level of strain. Fig. 15 clearly shows, likewise in Fig. 11, that doubling the thickness of the specimen results in a high reductions in sample strain the fiber structure than the metallic structure.
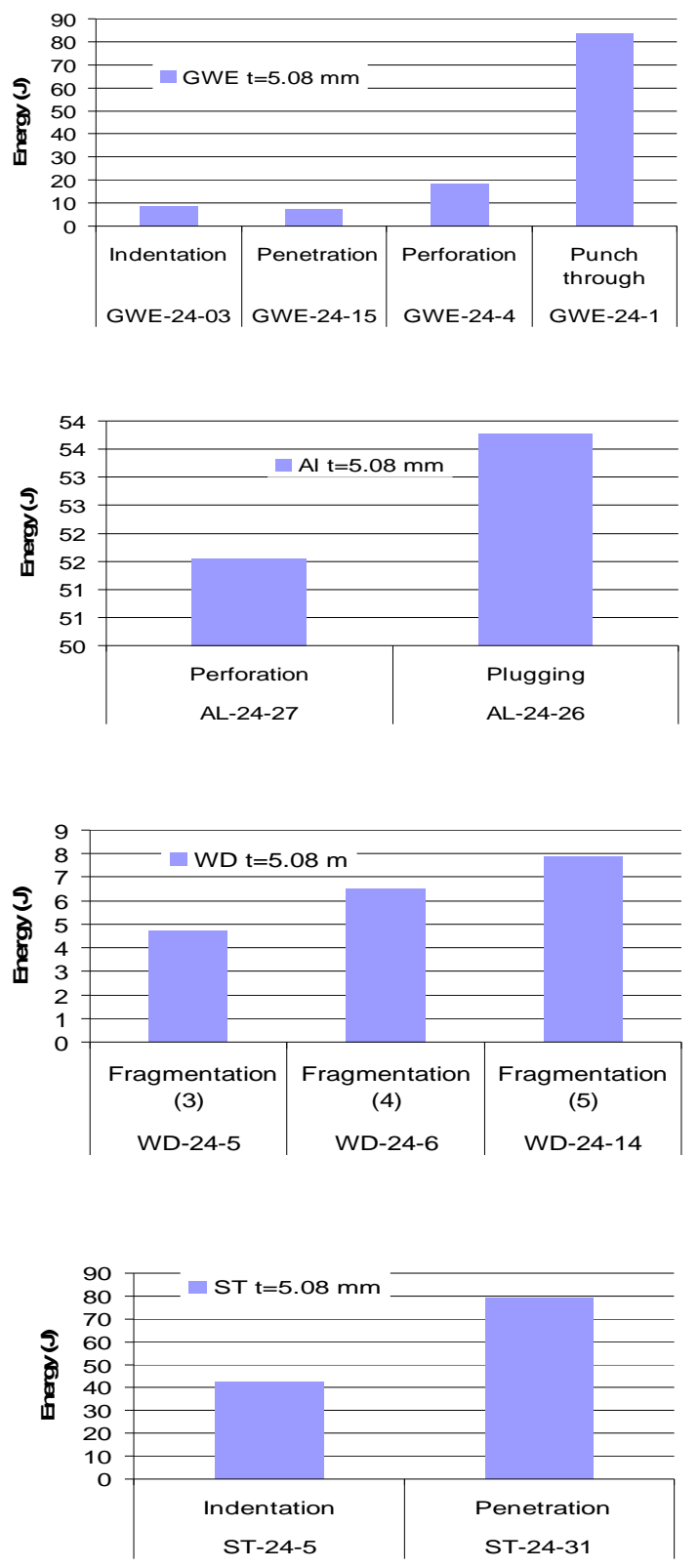

Fig. 14 Maximum energy absorbed by specimen of different material and thicknesses for dynamic damage type in an impact experiment 

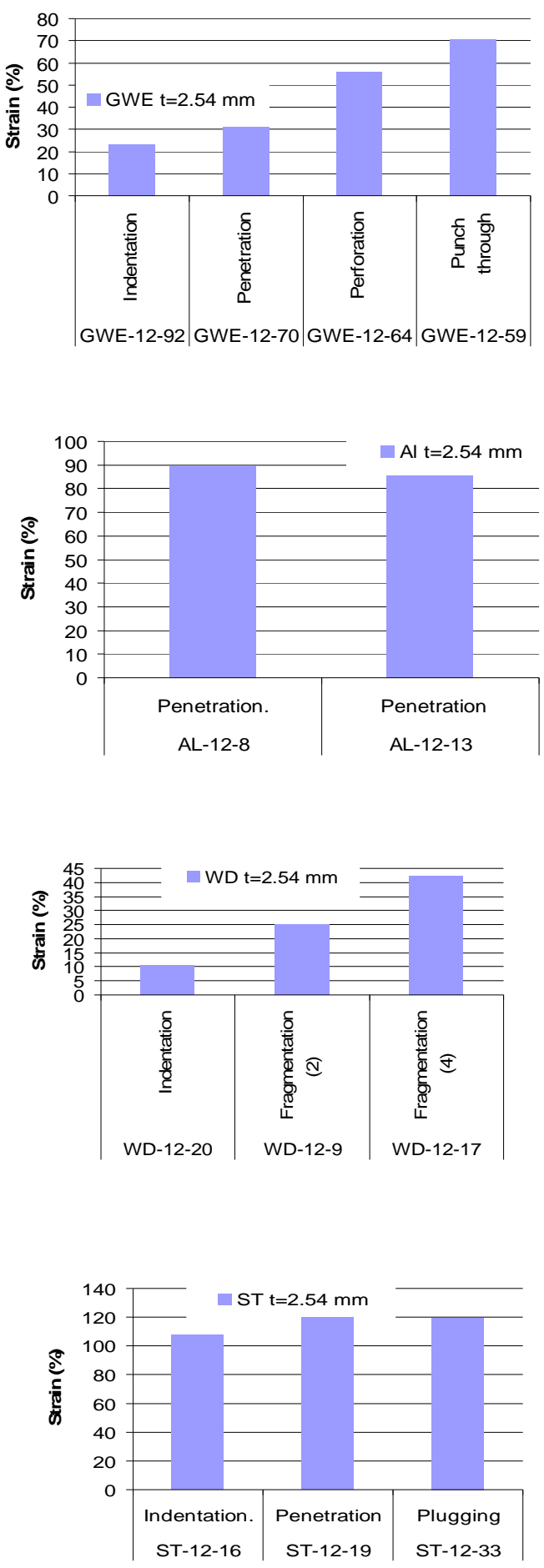
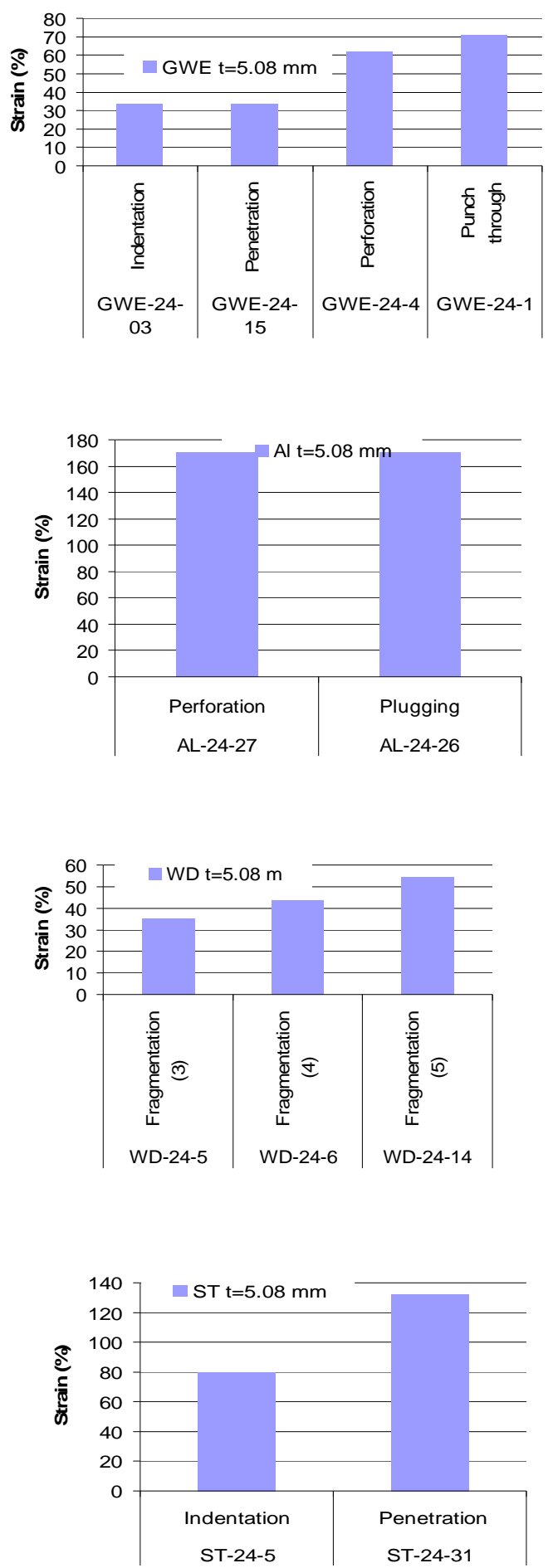

Fig. 15 Maximum strain in specimen of different material and thicknesses for dynamic damage type in an impact experiment

Higher strain is obtained in higher energy events (e. g. punch-through damage mode) than in lower energy event (e. g. indentation and low fragmentation even) in wood and composites. Characteristic results of each test are presented in Table III and Table IV. It is intuitively understandable that absorption of major energy lost between reflected and transmitted waves by the specimens, causes one of the six different damage modes.
Threshold of applied energy is very critical and the results might change drastically by any small deviation depending on the material. The numerical results reveal that the maximum strain rate of the specimen has relationship with the absorbed energy of the specimen passes its critical yield point and it abruptly decreases as the material reaches the relaxing absorbed energy point in the graph. 
TABLE III MECHANICAL PROPERTIES OF SPECIMENS.

\begin{tabular}{cccccccc}
\hline Sample Id & $\begin{array}{c}\text { Strain rate } \\
\mathbf{( 1 / m )}\end{array}$ & $\begin{array}{c}\text { Yield } \\
\text { strain } \\
\mathbf{( \% )}\end{array}$ & $\begin{array}{c}\text { Yield } \\
\text { stress } \\
\mathbf{( M P a )}\end{array}$ & $\begin{array}{c}\text { Modulus of } \\
\text { Elasticity } \\
\mathbf{( M P a )}\end{array}$ & $\begin{array}{c}\text { Yield } \\
\text { energy } \\
\mathbf{( J )}\end{array}$ & $\begin{array}{c}\text { Relaxing } \\
\text { energy } \\
\mathbf{( J )}\end{array}$ & $\begin{array}{c}\text { Energy } \\
\text { at 400 ns }\end{array}$ \\
\hline AL-12-13 & 4.12 & 32 & 7.24 & 1.45 & 24.34 & 32.85 & 32.38 \\
AL-12-8 & 3.25 & 24 & 7.24 & 1.09 & 17.45 & 12.98 & 10.33 \\
AL-24-26 & 2.18 & 40 & 16.55 & 0.79 & 27.84 & 47.10 & 45.47 \\
AL-24-27 & 2.20 & 38 & 16.55 & 0.75 & 29.34 & 46.12 & 44.61 \\
GWE-12-59 & 3.22 & 2 & 0.55 & 1.19 & 19.40 & 18.68 & 18.31 \\
GWE-12-64 & 1.81 & 2 & 0.41 & 1.58 & 6.46 & 7.18 & 7.13 \\
GWE-12-70 & 1.59 & 1 & 0.41 & 0.79 & 3.63 & 4.49 & 4.45 \\
GWE-12-92 & 1.15 & 2 & 0.55 & 1.19 & 2.42 & 2.58 & 2.56 \\
GWE-24-1 & 1.69 & 1 & 0.48 & 0.68 & 18.29 & 23.67 & 23.73 \\
GWE-24-03 & 0.88 & 3 & 0.55 & 1.78 & 5.88 & 7.06 & 6.95 \\
GWE-24-15 & 0.88 & 3 & 0.62 & 1.58 & 4.72 & 7.05 & 6.90 \\
GWE-24-4 & 1.48 & 3 & 0.62 & 1.58 & 12.98 & 17.68 & 17.62 \\
WD-12-17 & 2.04 & 0 & -0.12 & 0.00 & 4.01 & 4.13 & 4.19 \\
WD-12-20 & 0.45 & 0 & -0.12 & 0.00 & 0.39 & 0.23 & 0.21 \\
WD-12-9 & 1.20 & 0 & -0.12 & 0.00 & 1.97 & 1.14 & 1.12 \\
WD-24-14 & 1.21 & 0 & -0.25 & 0.00 & 6.12 & 4.92 & 5.00 \\
WD-24-5 & 0.80 & 0 & -0.25 & 0.00 & 4.33 & 3.24 & 3.23 \\
WD-24-6 & 0.99 & 0 & -0.25 & 0.00 & 5.65 & 4.72 & 4.71 \\
ST-24-31 & 3.41 & 25 & 17.24 & 0.48 & 57.86 & 67.92 & 62.76 \\
ST-24-5 & 1.87 & 22 & 15.86 & 0.45 & 17.40 & 39.72 & 36.99 \\
\hline
\end{tabular}

TABLE IV NUMERICAL ANALYSIS DATA OF THE CAPTURED WAVES FOR ALL SPECIMENS.

\begin{tabular}{cccccccc}
\hline $\begin{array}{c}\text { Specimen } \\
\text { ID }\end{array}$ & $\begin{array}{c}\text { Stress-inc. } \\
\text { (MPa) }\end{array}$ & $\begin{array}{c}\text { Stress-ref. } \\
\mathbf{( M P a )}\end{array}$ & $\begin{array}{c}\text { Stress- } \\
\text { strain. } \\
\mathbf{( M P a )}\end{array}$ & $\begin{array}{c}\text { Force } \\
\mathbf{( k N )}\end{array}$ & $\begin{array}{c}\text { Ultimate } \\
\text { energy } \mathbf{( J )}\end{array}$ & $\begin{array}{c}\text { Penetration } \\
\mathbf{( m m})\end{array}$ & $\begin{array}{c}\text { Velocity } \\
(\mathbf{m} / \mathbf{s})\end{array}$ \\
\hline AL-12-13 & 231.94 & 20.13 & 31.16 & 116.54 & 37.59 & 2.20 & 10.11 \\
AL-12-8 & 175.40 & 87.43 & 52.68 & 92.40 & 19.49 & 1.40 & 8.05 \\
AL-24-26 & 252.07 & 108.94 & 46.61 & 128.83 & 52.23 & 2.30 & 10.93 \\
AL-24-27 & 248.21 & 89.91 & 47.71 & 130.92 & 50.54 & 2.20 & 10.83 \\
GWE-12-59 & 181.19 & 34.75 & 5.79 & 100.35 & 24.77 & 1.90 & 8.04 \\
GWE-12-64 & 100.66 & 8.55 & 6.07 & 46.62 & 8.23 & 1.10 & 4.63 \\
GWE-12-70 & 81.36 & 4.14 & 6.07 & 43.27 & 4.63 & 0.90 & 3.93 \\
GWE-12-92 & 67.84 & 2.21 & 4.96 & 30.85 & 2.67 & 0.60 & 2.84 \\
GWE-24-1 & 192.78 & 20.96 & 12.41 & 100.35 & 26.93 & 1.90 & 8.46 \\
GWE-24-03 & 92.11 & 2.76 & 11.58 & 47.32 & 8.28 & 0.90 & 4.39 \\
GWE-24-15 & 92.11 & 2.76 & 11.58 & 47.59 & 7.54 & 0.90 & 4.38 \\
GWE-24-4 & 166.03 & 17.10 & 12.69 & 87.09 & 18.37 & 1.70 & 7.43 \\
WD-12-17 & 107.28 & 6.34 & 1.38 & 54.71 & 4.97 & 1.20 & 4.93 \\
WD-12-20 & 23.72 & 2.76 & 0.55 & 13.12 & 0.43 & 0.30 & 1.13 \\
WD-12-9 & 60.67 & 5.79 & 1.93 & 33.36 & 2.09 & 0.70 & 2.90 \\
WD-24-14 & 122.73 & 7.45 & 3.03 & 59.46 & 6.92 & 1.40 & 5.86 \\
WD-24-5 & 80.81 & 6.62 & 2.76 & 40.89 & 4.58 & 0.90 & 3.95 \\
WD-24-6 & 104.80 & 8.27 & 13.24 & 53.88 & 6.23 & 1.20 & 4.85 \\
ST-24-31 & 361.01 & 103.15 & 76.95 & 213.97 & 75.07 & 3.30 & 16.49 \\
ST-24-5 & 215.67 & 132.93 & 64.53 & 121.01 & 42.58 & 1.80 & 9.41 \\
\hline
\end{tabular}


Plastic deformation of the specimen is proportional to the striker impact velocity. Fiber arrangement gives woven composites higher strength than wood. Failing of fibers in wood is without elastic deformation but in woven composites, an elastic field within the deformation zone is first created and then breaks. That is the reason for having more gradual stepping in stress strain graphs for woven composites compared to wood. Materials with higher ductility property have lower yield stress, ultimate stresses, and higher strain. Thicker materials have higher ultimate stress and ultimate strain. Aluminum, steel and woven graphite epoxy composites have the ability to localize damage, whereas, wood breaks into fragments without any intermediate damage modes after indentation. These facts for fiber and metallic structure material can be seen for all four critical energy levels.

Results demonstrate that absorbed energy by the material is a good material characteristic to be used in design for predicting the level of dynamic damage. The defined strain may not be appropriate for this prediction because the crystal structure and atomic bonds of the material increase the strength and ductility properties of material and, consequently, presents a different type of damage for the same strain in different materials. A certain level of strain hardening is observed in both metallic and fiber structure. Plastic deformation and especially crack formation and propagation produce a large drop in absorbed stress level in the material for the same strain rate.

\section{CONCLUSIONS}

The P-SHPB system was used to investigate the dynamic failure of steel, aluminum wood, and WGEC material. Specimens were fabricated in two different thicknesses for each material to compare the effect of the geometrical dimension on the behavior of different material in high strain failure for material with different constituent structure. The damage on the specimen is visually categorized as one of the six visible damage modes: indentation, penetration, perforation, punch through, plugging, and fragmentation. The energy levels and the compressive dynamic failure behavior of the materials were investigated. Four critical modes of failure characteristic of material were defined and shown to be occurred based on the incident energy, strain rate, geometrical dimension, and material structure. The following conclusions can be made from the results:

1. Incident stress is proportional to striker impact energy but independent of disk thickness. The particle velocity and loading force on the specimen linearly depend on the incident stress. The energy transferred to the specimen in the damage process, increases with increase in incident stress.

2. The effect of thickness in energy absorbed is not the same for materials of different atomic structure, while the amount of the absorbed energy has a direct relationship with metallic structure in aluminum and steel. Doubling the thickness of the specimen, results in higher $(50 \%)$ reductions in sample strain in the fiber structure than $(25 \%)$ reduction the metallic structure.
3. Higher strain is obtained in higher energy events (such as in punch-through damage mode) than in lower energy event (such as indentation and low fragmentation events in composites and wood); the fiber structures have the same reduction in strain that is two times that of metallic structure.

4. The relation between energy absorbed and damage mode shows that the deformation in the specimens is increased as the specimen's ultimate energy absorbed gets larger which results in more catastrophic damage in high strain rate plastic deformation.

5. Energy absorbed is a good characteristic parameter to predict the damage. The dependency of deformation on energy absorption follows a power law for the woven composite and is approximated with linear relationships for aluminum and steel.

\section{REFERENCES}

[1] Hanpu, Yang, "Corrosion study on dual phase 0. 08CCu-P-Cr-Ni-Mo", Kang T'ieh/Iron and Steel, v 23, n 1, Jan, 1988, p 44-51.

[2] Nagashima, S. "Anisotropy in mechanical properties and texture control in steel making technology." Netherlands Soc for Materials Science, 1984, p 369-382.

[3] Jiao, Chu-Jie, Sun, Wei; Gao, Pei-Zheng. "Dynamic mechanical properties of steel-fiber reinforced ultra high strength concrete" Gongcheng Lixue/Engineering Mechanics, v 23, n 8, August, 2006, p 86-89+85.

[4] Yu, M.T., Topper, T.H., "The effects of material strength, stress ratio, and compressive overload on the threshold behavior of SAE1045 steel", Journal of engineering material and technology, Vol. 107 (1985) pp 19-25.

[5] Yoshida, F., Uenori, T., and Fujiwara, K., "Elasticplastic of steel sheets under in-plane cyclic tensioncompression at large strain", International journal of plasticity, Vol. 18 (2002) 633-659.

[6] Zhang, Henghua; Tang, Xuan. "Microstructure and mechanical properties of purity aluminum refined with salt containing Ti and B elements" JSME International Journal, Series A: Solid Mechanics and Material Engineering, v 49, n 1, Jul 15, 2006, p 95-99.

[7] Li, Wen-Sheng, Wang, Zhi-Ping, "Preparation, mechanical properties and wear behaviors of novel aluminum bronze for dies" Transactions of Nonferrous Metals Society of China (English Edition), v 16, n 3, June, 2006, p 607-612.

[8] Takaai, Tetsuya, Nakayama, Yoshihiro. "Tensile properties of 1050 aluminum plate at cryogenic temperatures" Keikinzoku/Journal of Japan Institute of Light Metals, v 39, n 10, Oct, 1989, p 717-723.

[9] Ushigome, Susumu, Yamamoto, Kungi. "Mechanical properties of $\mathrm{SiC}$ particle reinforced aluminum alloy composite" Tetsu-To-Hagane/Journal of the Iron and Steel Institute of Japan, v 75, n 9, Sep, 1989, p 15491554.

[10] Wang, Zhi-Hua, Cao, Xiao-Qing; Ma, Hong-Wei. 
"Experimental studies on the dynamic compressive properties of open-celled aluminum alloy foams" Baozha Yu Chongji/Explosion and Shock Waves, v 26, n 1, January, 2006, p 46-52.

[11] Jia, D., Ramesh, K.T., "Rigorous assessment of the benefits of miniaturization in the Kolsky bar system", Society of experimental mechanics, 2004.

[12] Lee, S., Barthelat, F., and Espinosa, H.D., "Strain rate effects in metallic cellular materials", Proceedings of the 2003 SEN annual conference and exposition on experimental and applied mechanics, June 2-4, charlotte, North Carolina, session 37, paper 188, 2003.

[13] Vural, N., Ravichandran, G., "Dynamics response and energy dissipation characteristics of balsa wood: experiment and analysis", International journal of solids and structures, Vol. 40 (2003) pp 2147-2170.

[14] Cantero, G., and Ardelaiz, A., Mugika, F., Valea, A., and Mondragon, I., "Mechanical behavior of wood/polypropylene composites: effects of fiber treatments and aging processes", Journal of reinforced plastics and composites, Vol. 22, No.1/2003, pp 37-50.

[15] Khan, Mubarak Ahmad, Ali, K.M. Idriss. "Studies of physico-mechanical properties of wood and wood plastic composite (WPC)" Journal of Applied Polymer Science, v 45, n 1, May 5, 1992, p 167-172.

[16] Dhubhain, A. Ni , Evertsen, J. A. . "Influence of compression wood on the strength properties of Sitka Spruce.”, Forest Products Journal, v 38, n 9, Sep, 1988, p 67-69.

[17] Okai, R. , Frimpong-Mensah, K. "Characterization of mechanical strength properties of coconut wood infested with the Cape St Paul Wilt disease" International Journal of Advanced Manufacturing.

[18] Jiang, Banghai, Zhang, Ruoqi. "Experimental study on the interlaminar tensile properties for a kind of carbon fiber woven reinforced composite under impact loading." Fuhe Cailiao Xuebao/Acta Materiae Compositae Sinica, v 22, n 5, October, 2005, p 107-112.

[19] Yang, Caiyun, Liu, Yong. "Experimental evaluation of the influence of structural parameters on tensile properties of 3D woven composites." Fuhe Cailiao Xuebao/Acta Materiae Compositae Sinica, v 23, n 1, February, 2006, p 85-91.

[20] Fujita, K. , Hamada, Hiroyuki. "Tensile properties of carbon fiber triaxial woven fabric composites." Journal of Composite Materials, v 27, n 15, 1993, p 1428.

[21] Zhou, Ping, Wu, Chengwei. "Transverse mechanical properties of plain woven fabric composites" Fuhe Cailiao Xuebao/Acta Materiae Compositae Sinica, v 23, n 3, June, 2006, p 170-175.

[22] Kim, Jaehyun, Shioya, Masatoshi. "Mechanical properties of woven laminates and felt composites using carbon fibers." Part 1: In-plane properties" Composites
Science and Technology, v 64, n 13-14, October, 2004, p 2221-2229.

[23] Ramnath, V. "Elastic properties of woven fabric reinforced composits" Collection of Technical Papers AIAA/ASME/ASCE/AHS Structures, Structural Dynamics \& Materials Co, n pt 1, 1985, p 420-425.

[24] Mitrovic, Milan, Carman, Greg P. "Effect of fatigue damage in woven composites on thermo-mechanical properties and residual compressive strength" Journal of Composite Materials, v 30, n 2, 1996, p 164-188.

[25] Alamdar-Yazdi, A. "Shearing properties of the skewed woven fabrics" International Journal of Engineering, Transactions A: Basics, v 18, n 2, May, 2005, p 177182.

[26] Bamisaye, O.O., "Effect of penetrator configuration and size on the dynamic behavior of composite material under high strain rate loading", University of Pittsburgh, Department of Mechanical engineering Master thesis, 2003.

[27] Nwosu, S.N., "Survivability studies: High-energy penetration/perforation mechanics of composite plates using an integrative split penetration Hopkinson pressure bar and high speed optical imaging system", Tuskegee University final report 03-31.

[28] Allazadeh M. R., Itani K Maher, Wosu Sylvanus N. ;"Characterization of Compressive Damage Behavior of Steel and Aluminum"; Journal of Materials Science Research, Vol. 1, No. 1, January 2012.

[29] Allazadeh M. R., Wosu Sylvanus N. ;"High Strain Rate Compressive Tests on Woven Graphite Epoxy Composites" Chemistry and Materials Science, Applied Composite Materials, Volume 18, Number 4, pp: 311325, (August 2011), DOI: 10.1007/s10443-010-9159-6.

[30] Allazadeh M. R., Wosu Sylvanus N.;" High Strain Rate Compressive Tests on Wood"; Strain, An international Journal for Experimental Mechanics, STRAIN(January 2011), DOI: 10.1111/j.1475-1305.2010.00802.

[31] Ojo O. B., Wosu S. N., Onipede D., Slaughter W., "Effect of Penetrator Size on the Dynamic failure Response of Woven Graphite Epoxy Composites around the critical Perforation Energy" J. ASTM International, Vol. 4, No. 4, 2007.

[32] Kolsky, H;" An Investigation of the Mechanical Properties of Materials at Very High Rates of Loading'; Proceedings of the Royal Society of London 1949, B62, 676-700.

[33] Bickle, L. W., "An Introduction of the Use of Strain Gages for the Measurement of Propagating Strain Wave", Sandia Laboratories, Albuquerque, Mew Mexico (1970).

[34] Zukas J. A. et al, Impact Dynamics, Wiley, NY, ISBN 0-89464-661-3; 1982; reprinted 1992 by Krieger Publishing, Malabar, FL. 